Note to ITAR reviewers: Underlined text on pages 1, 3 through 7, and 13 was previously approved for public release in the following publications:

J. L. Goodman, "Space Shuttle Navigation in the GPS Era," Proceedings of the Institute of Navigation National Technical Meeting, Institute of Navigation, Fairfax, VA, 2001.

J. L. Goodman, GPS Lessons Learned From The ISS, Space Shuttle and X-38, NASA Contractor Report NASA/CR-2005-213693, NASA Johnson Space Center, November 2005. 


\title{
Operational Use of GPS Navigation for Space Shuttle Entry
}

\author{
John L. Goodman \\ Carolyn A. Propst \\ United Space Alliance, LLC \\ 600 Gemini Ave. \\ Houston, TX, 77058
}

\begin{abstract}
The STS-118 flight of the Space Shuttle Endeavour was the first shuttle mission flown with three Global Positioning System (GPS) receivers in place of the three legacy Tactical Air Navigation (TACAN) units. This marked the conclusion of a 15 year effort involving procurement, missionization, integration, and flight testing of a GPS receiver and a parallel effort to formulate and implement shuttle computer software changes to support GPS. The use of GPS data from a single receiver in parallel with TACAN during entry was successfully demonstrated by the orbiters Discovery and Atlantis during four shuttle missions in 2006 and 2007 . This provided the confidence needed before flying the first all GPS, no TACAN flight with Endeavour. A significant number of lessons were learned concerning the integration of a software intensive navigation unit into a legacy avionics system. These lessons have been taken into consideration during vehicle design by other flight programs, including the vehicle that will replace the Space Shuttle, Orion.
\end{abstract}

\section{INTRODUCTION}

On August 21, 2007, the Space Shuttle Endeavour ended the STS-118 mission with a successful entry and landing using three GPS receivers in place of three legacy TACAN units. Space Shuttle entry navigation performance has been excellent since the first shuttle mission in 1981. However, in 1993 the planned phase-out of TACAN in favor of GPS starting in the year 2000 motivated the Shuttle Program to select a GPS receiver for TACAN replacement. The shuttle was originally scheduled to fly the first all GPS, no TACAN flight in mid 1999. However, delays in the start of TACAN phase-out, a desire to conduct additional flight and ground testing before shuttle GPS certification, the continued excellent performance of the legacy entry navigation system, and the loss of the shuttle Columbia delayed the use of GPS during entry and landing. Had the TACAN phase-out start dates specified in successive editions of the Federal Radionavigation Plan not slipped, the Shuttle Program would have pursued a more aggressive GPS implementation schedule.

The Space Shuttle performs winged hypersonic entry and unpowered runway landings. This was a significant change from the ballistic and low lift-to-drag ratio entries and parachute landings into the ocean performed during the Mercury, Gemini, Apollo, Skylab, and Apollo-Soyuz programs. Consequently, the avionics and navigation architecture for the shuttle was more complex and had more redundancy than the Mercury, Gemini, and Apollo spacecraft. GPS was integrated into the flight proven shuttle avionics system in a manner that did not compromise the certification status or performance of the legacy system [1] [2]. While many avionics units from aviation were adapted for the shuttle in the 1970s, none were as complex in terms of software as a GPS receiver. Many lessons were learned that are being applied to other flight programs, including the development of the new NASA human flight vehicle, Orion [3-7].

This paper contains an overview of entry navigation for the Mercury, Gemini, Apollo, and shuttle vehicles, enabling the reader to understand how different mission requirements drove navigation system redundancy and capability. The shuttle GPS integration architecture is discussed, along with the flight test program. A summary of GPS performance on four GPS ramp-up flights, immediately preceding the first TACAN replacement flight, is given. Finally, performance results from the STS-118 flight of Endeavour are discussed.

\section{SUMMARY OF MERCURY, GEMINI, AND APOLLO ENTRY NAVIGATION}

\section{A. Mercury}

The primary objective of Project Mercury was to determine if a human could function in space. The Mercury spacecraft did not have an on-board navigation system as found on later vehicles, nor did it have a digital computer. Mercury was equipped with sensors for attitude determination and maintenance. These sensors included a two degree-of-freedom directional gyro, a two degree-offreedom vertical gyro, a $0.05 \mathrm{~g}$ accelerometer switch, and infra-red horizon scanners that provided roll and pitch data for alignment of the attitude gyros.

Beyond the deorbit burn, Mercury did not have the ability to modify the orbit in a targeted fashion, although small solid propellant rockets were fired during separation from the Atlas booster. Ground tracking and orbit determination was used to determine the time of ignition of the retro-rockets for deorbit. This time was transmitted to the vehicle. The deorbit burn essentially aimed the spacecraft for the desired 
splashdown point. Retro fire could be commanded automatically or manually by the astronaut. The splashdown location was selected so that ground tracking could be performed after retro fire. This data was used to ensure that recovery forces had accurate knowledge of where the capsule would land.

A ballistic entry profile minimized requirements for the autopilot, guidance, and control. The vehicle rolled during entry to cancel out any lift effects caused by center of mass dispersions. These dispersions could cause the vehicle to fly at a non-zero angle of attack and result in a small amount of lift, causing the vehicle to miss the targeted splashdown point.

The experience gained by mission operations, engineering, management, and software personnel during Project Mercury proved to be invaluable and was directly applied to the development of navigation techniques and tracking network architectures used in the Gemini and Apollo Programs.

\section{B. Gemini}

Programmatic objectives of the Gemini Program required a more complex and capable on-board navigation system than Mercury. These objectives included manually piloted and automated lifting entry to reach a targeted splashdown point, and rendezvous and docking.

A lifting capsule was achieved by intentionally offsetting the center of mass. On-board avionics hardware used during entry included a digital flight computer, a four-gimbal stable member Inertial Measurement Unit (IMU), and rate gyros for use in the event of an IMU failure during entry. Before deorbit, the IMU was aligned to an inertial frame using two redundant Earth horizon sensors. The Gemini computer propagated a state vector during entry for use by the entry guidance algorithm. In case of an IMU failure, backup rate gyro data and out-the-window monitoring of the Earth horizon were available to support manual piloting. The manual procedure consisted of flying ground supplied constant bank angles, with bank angle reversals at ground specified times.

Gemini had a ballistic entry mode similar to Mercury. The vehicle was continuously rolled to cancel out the lift effect from the offset center of gravity. Two lifting entry modes shaped the descent trajectory by modulating the lift vector to reduce and control predicted down-range and cross-range errors. The first mode maintained a constant bank angle to control the lift vector to reduce the predicted down-range error at the target point. Cross-range control was achieved by rolling the vehicle to reverse the sign of the constant bank angle value. This technique was similar in concept to that flown later by Apollo and the Space Shuttle. The second mode was called rolling entry. It flew a lifting entry to place the vehicle on a ballistic trajectory that would reach the target point. Once the vehicle achieved the conditions necessary for the ballistic trajectory, it was continuously rolled to cancel out the lift vector.
Both of the lifting modes could be flown manually by the crew based on roll, pitch, and yaw commands determined by the on-board computer and presented to the crew on cockpit displays. The last two Gemini missions (11 and 12) flew the rolling entry mode automatically. On Gemini 4 the crew flew manually based on procedures and cockpit instruments, but without the benefit of computer generated piloting cues due to a computer failure. On other Gemini missions the crew flew manually using computer cues.

\section{Apollo}

The Apollo Guidance, Navigation, and Control (GNC) system was designed to support entry from three types of trajectories. These included entry from a near circular low Earth orbit (Apollo, Skylab, Apollo-Soyuz), Apollo highly elliptical Earth orbit aborts after Trans-Lunar Injection, and Apollo lunar return trajectories. A skip entry capability was developed to enable the vehicle to reach an alternate landing site, in the event of weather concerns at the primary landing site. A digital computer maintained estimates of translational and rotational states. A three axis stable member IMU provided inertial measurements. Like Gemini, IMU data was the only sensor data used to maintain the state vector during entry. Guidance algorithms in the computer could be used either to automatically fly the vehicle or provide the crew with piloting cues for manual flying. The limited on-board computer memory capacity had a great impact on software requirements, software architecture, and algorithm choices. Navigation data was used by entry guidance. However, a skip entry was never flown on a crewed Apollo mission, in part due to limited navigation system accuracy.

The crew could take over at any point in the event of a computer or an IMU failure. The Entry Monitoring System (EMS) provided manual piloting cues independent of the primary GNC system. The EMS contained a single accelerometer. EMS accelerometer data was used to compute a velocity estimate independent of the primary GNC system. Rate gyros in the Spacecraft Stabilization System provided backup attitude data to the crew. In the event of both primary GNC and EMS failures, the crew flew a constant $g$ bankreverse-bank trajectory using a secondary g meter and a roll attitude display. If all sources of attitude reference data were lost, a rolling ballistic entry could be flown.

All crewed Apollo missions automatically flew lifting entries to sites that did not require a skip. There were no primary GNC failures.

\section{SPACE SHUTTLE ENTRY NAVIGATION}

\section{A. The Shuttle Compared to Gemini and Apollo}

For a spacecraft to fly from Mach 25, at orbital altitude to an unpowered runway landing, required a much more complex GNC system for entry and landing than previous vehicles. Like Gemini and Apollo, the Shuttle controls down-range and cross-range error during entry by rolling the lift vector about the velocity vector. Also, like Gemini and 
Apollo, the shuttle uses RCS jets to control rotational motion.

Aero surfaces become active when there is sufficient dynamic pressure for them to be effective. RCS jets are deactivated on a per axis basis when specified dynamic pressure levels are reached. While Apollo was statically stable in pitch and yaw during entry, the Shuttle orbiter was designed to be statically unstable in pitch and yaw over most of the flight envelope. This necessitates the use of computer algorithms for flight control for both automated and semiautomatic human-in-the-loop flight.

The winged configuration of the Space Shuttle gave it an entry cross-range capability much greater than the Gemini and Apollo capsules. The shuttle entry and landing trajectory is designed to prevent violations of vehicle constraints on the thermal protection system, structural loading, dynamic pressure, and aero surface hinge moments. Furthermore, the vehicle must fly a trajectory that permits stable flight without excessive expenditure of RCS and Auxiliary Power Unit propellant. The entry and landing guidance algorithms must compute an accurate estimate of range to runway based on navigation data. Navigation data of sufficient accuracy is required to ensure that the vehicle can adequately control the atmospheric drag and energy of the vehicle and remain within the previously mentioned constraints.

\section{B. Shuttle Navigation Flight Testing}

The shuttle entry navigation system was exercised for the first time throughout the entire flight envelope on the first human flight (STS-1, April 1981). This was a different approach than the Mercury, Gemini, and Apollo Programs. Entry GNC systems of those vehicles were tested on unmanned flights before the first manned mission. Some limited flight testing of shuttle entry navigation sensors was conducted before STS-1. The Microwave Landing System, TACAN, and air data sensors were tested during the Approach and Landing Tests of the orbiter Enterprise at Edwards Air Force base in 1977. TACAN tests were also conducted by a USAF SR-71 flying a profile similar to that of the shuttle.

\section{Shuttle Flight Computers}

Redundant computers are used instead of the Gemini and Apollo single string computer architecture. However, unlike Gemini and Apollo, the Shuttle requires the use of a computer to perform guidance, navigation and control functions during entry. The shuttle had the first human rated Fail Operational/Fail Safe (FO/FS) avionics architecture to preserve mission options after the first failure. This resulted in a more complex and robust avionics system than Gemini and Apollo.

For ascent and entry, five GNC computers are used. A redundant set of four computers contain the Primary Avionics Software System (PASS). The fifth runs Backup Flight Software (BFS). The BFS, coded by a different contractor than the PASS, contains a subset of the PASS functionality to enable the vehicle to finish nominal ascent, an abort, or landing in the event of a generic PASS software failure. Multiple navigation sensors, command paths, and power buses within the avionics system ensure redundancy.

Unlike Gemini and Apollo, the manual pilot-in-the-loop mode of entry and landing requires a computer. There are no back-up flight modes in the event that all four PASS and the single BFS computer fail. Shuttle entry is flown automated with pilot-in-the-loop control as backup mode. Just below Mach 1 pilot-in-the-loop control commences. Automated flight is a back-up method for final approach and landing [7].

\section{Shuttle Navigation Architecture}

The shuttle entry navigation approach was significantly different than Gemini and Apollo. Shuttle entry navigation required the use of other navigation aids in addition to IMUs [2]. The accelerometer and gyro errors and biases from stateof-the-art IMUs would not permit a safe entry and runway landing using IMU only navigation.

A state vector uplink is performed before the deorbit burn to both the PASS and BFS flight software. This uplink is based on Mission Control processing of ground $\mathrm{C}$ Band radar (range and angles) and Tracking and Data Relay Satellite System (TDRSS) Doppler data.

Entry navigation sensors are depicted in Fig. 1. Redundant measurements from three High Accuracy Inertial Navigation System Inertial Measurement Units (HAINS IMUs), three TACANs, four barometric altimeters, and three Microwave Landing System (MLS) units are passed through Fault Detection, Identification, and Reconfiguration (FDIR)

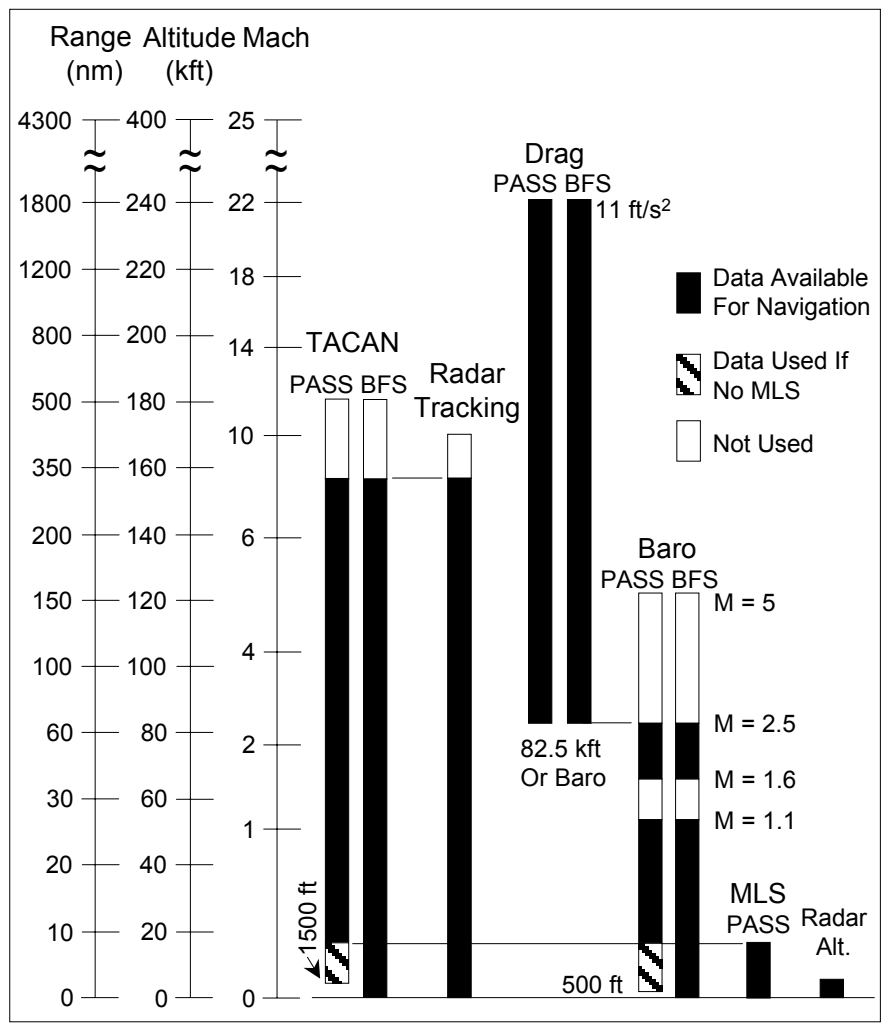

Fig. 1. Shuttle legacy entry navigation sensors. 
algorithms. Selection filters then process data from units deemed to be good. Selected measurements are then passed to the shuttle PASS and BFS navigation software, that processes the data using Kalman filters. Radar altimeter data is used for pilot situational awareness only and is not incorporated into the shuttle navigation state.

The first navigation filter measurement to be processed is drag altitude. Accumulated sensed delta velocity data from the IMUs are processed to estimate atmospheric density and an estimate of altitude is obtained from an atmosphere model. Drag altitude measurements are inaccurate, but bound vertical position error growth in the event of other navigation system failures.

Kalman filter processing of selected TACAN range and bearing measurements begins at a range no greater than 400 nautical miles from the runway and an altitude of roughly $145,000 \mathrm{ft}$ for a nominal entry and landing. TACAN bearing is not processed when the elevation angle of the slant range is 35 degrees or greater, a region known as the cone of confusion. Radar tracking is normally established in time for Mission Control to assess the TACAN units and navigation state vector health before TACAN measurement processing commences in the PASS and BFS computers. Measurements from two radars are required to ensure a good ground tracking solution.

Before the loss of Columbia ground radar tacking during entry was highly desirable and required if there were hardware failures on the vehicle. Following the loss of the shuttle Columbia, ground radar tracking during entry and landing is mandatory for the remainder of the flight program.

Significant navigation errors during entry can exceed the ability of the guidance and flight control system to fly the orbiter to the landing site. Guidance constraints define the maximum allowable state error. If radar tracking indicates that navigation errors are excessive, Mission Control can perform an emergency state vector correction uplink to the orbiter, called a delta state update. In the event of a navigation error that exceeds the constraints, the delta state update is uplinked directly to the PASS flight software or voiced to the crew for manual entry on a cockpit display. The BFS navigation state is then corrected by transferring the PASS state to the BFS. A delta state update has never been executed in flight, but is frequently practiced in training simulations by Mission Control personnel.

Drag altitude processing ends once barometric altimeter processing begins. Two air data probes each provide two independent measurements. Kalman filter processing of air data begins at Mach 2.5 and an altitude of about $85,000 \mathrm{ft}$. Barometric altimeter processing is inhibited between Mach 1.6 and Mach 1.1, during the Mach jump region.

PASS Kalman filter processing of MLS range, azimuth and elevation data usually begins at an altitude of around 17,000 ft. Once MLS is acquired, PASS stops processing TACAN and barometric altimeter data and shifts from maintaining three state vectors to one. For a landing site not equipped with MLS, PASS processing of TACAN stops at an altitude of $1,500 \mathrm{ft}$ and barometric altimeter processing continues until $500 \mathrm{ft}$. BFS does not process MLS, but will process TACAN and baro data all the way to landing.

\section{SPACE SHUTTLE GPS UPGRADE}

\section{A. TACAN Phase-out and Receiver Selection}

By the early 1990s, the approaching operational status of the GPS satellite constellation and advances in GPS receiver technology led to planning for deactivation of legacy radionavgiation aids. While Space Shuttle entry navigation performance has been excellent since the first shuttle mission in 1981, the eventual phase-out of TACAN in favor of GPS required a change to the shuttle navigation system.

The planned year 2000 start of TACAN phase-out motivated the Shuttle Program to select a GPS receiver that could be certified and flight proven by that year. In 1993, the five channel Miniaturized Airborne GPS Receiver (MAGR) was chosen for TACAN replacement. Existing space GPS receivers were not suitable for the shuttle from a weight and form factor perspective. The MAGR would enable the Shuttle Program to take advantage of the existing logistics base supporting high volume military production. The MAGR could accept inertial aiding, was capable of authorized operation, and the digital tracking loops could be modified with software changes, as opposed to hardware modifications. In addition, military Class B parts requirements were similar to those of the Shuttle Program. While an all-in-view receiver would have been preferable, aviation receivers with the above characteristics were not available until at least 1998. The MAGR version for the Shuttle is known as the MAGR/Shuttle or MAGR/S.

\section{B. GPS Integration Architecture}

GPS was integrated into the shuttle avionics system as a separate navigation system [1]. Periodic replacement of the shuttle navigation state vector with a selected GPS state vector avoided filtering GPS measurements or a position vector. There was a strong desire to avoid modification and re-certification of the flight proven entry navigation algorithms and Kalman filters in the PASS and BFS software. The state replacement architecture also permitted flying the GPS receiver in a test mode, without committing to use GPS for navigation. This was invaluable for testing the GPS receiver and associated shuttle flight software performance through the shuttle flight profile, from pre-launch on the pad to landing.

This integration architecture allows operation of a mixed fleet of GPS and TACAN hardware configurations with the same version of PASS and BFS flight software. Due to the schedule of Orbiter Major Modification activities, not all orbiters were equipped with the same number of GPS receivers at the same time. Configurations supported by the same version of shuttle flight software are: 
- Three TACANs and one GPS receiver (the single string configuration of Discovery and Atlantis).

- Three GPS units and no TACANs (the three string configuration of Endeavour).

- Three TACANs and no GPS (none of the orbiters now have this configuration).

GPS vectors undergo a quality assurance and selection process before a GPS update to the navigation state can be performed. PASS flight software subjects GPS state vectors to three Quality Assurance (QA) checks as follows:

- Each GPS receiver Figure of Merit (FOM) is below a threshold.

- Each current receiver state is compared with the previous receiver state propagated to the current time.

- The current receiver states are compared with each other (Endeavour only, not performed for single string).

If criteria for any of the QA tests are violated, that receiver's state is not a candidate for selection. State vectors from candidate GPS units are then processed in a selection filter. There are crew controls that allow these QA tests to be bypassed, if necessary. The BFS flight software uses a simpler QA and selection scheme than PASS does.

Once the QA checks are complete and a GPS state has been selected, there are two crew commanded methods for incorporating the selected GPS state into navigation. The first involves automatic incorporation at a flight phase dependent rate, if the selected GPS state is within a tolerance of the current navigation state. The selected GPS state vector overwrites the PASS or BFS navigation states. The second method, called a "force," ignores the comparison test with the current navigation state and incorporates (forces) the selected GPS state into navigation. Selected MAGR/S states do not have to be continuously incorporated into shuttle navigation to support entry and landing.

The GPS receivers are provided with position, velocity, and attitude aiding data from the shuttle flight software. In the PASS computers, one aiding state vector is propagated for all three receivers, using selected IMU data from candidates that have been screened by a FDIR algorithm. The single aiding state is periodically reset with the Shuttle navigation state.

The MAGR/S uses two antennas (Fig. 2), that are located under the thermal protection system. The single string configuration uses one on the top and one on the bottom of the crew compartment. Input from the antennas is passed through pre-amplifiers and a signal combiner before reaching the MAGR/S. Neither antenna switching nor attitude determination is performed. In the three string GPS

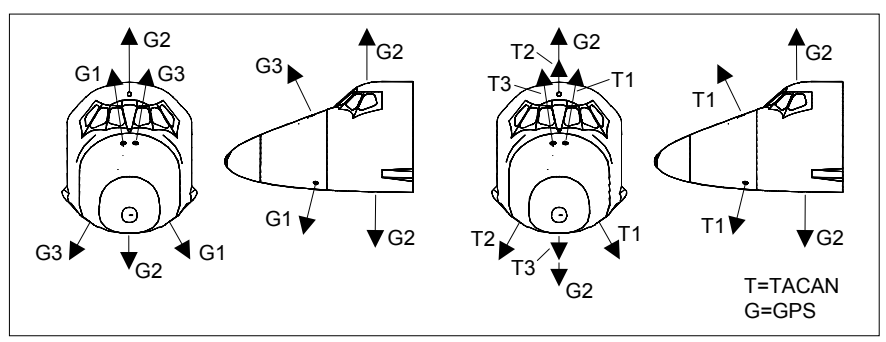

Fig. 2. Three string (left, Endeavour) and single string (right, Discovery and Atlantis) GPS antenna locations.

configuration, antennas for GPS strings 1 and 3 occupy the former positions of the TACAN strings 1 and 3 antennas.

\section{GPS Flight Tests}

The initial flight test program supporting TACAN replacement used the 5 channel $3 \mathrm{M}$ receiver, a pre-production MAGR. The 3M flew seven times from December 1993 to May 1996 on Endeavor (flights 61, 59, 68, 67, 69, 72 and 77, in launch order).

This series of flight tests was intended to determine if a GPS receiver designed for aviation use could function on the Space Shuttle with a minimum number of software changes. Some modifications were made to the $3 \mathrm{M}$ software between flights based on flight test results. Inertial Navigation System aiding data was supplied to the $3 \mathrm{M}$ by the BFS computer during ascent and entry, while on-orbit the receiver was unaided. Modifications were made to the MAGR/S based on $3 \mathrm{M}$ flight results.

From September 1996 to June 2002 the MAGR/S flew 25 times on the orbiters Columbia, Discovery, Atlantis, and Endeavour in support of the certification effort. On many flights, a laptop computer was used to record instrumentation port data, in addition to receiver data normally transmitted to Mission Control during a mission. This data greatly enhanced vendor efforts to track down and resolve complex software issues in the GPS receiver.

Test activities included astronaut execution of MAGR/S procedures. Selected MAGR/S state vectors were incorporated into the PASS and BFS flight software on several occasions while on-orbit. In December of 1999, before the deactivation of Selective Availability, the MAGR/S was intentionally unkeyed before entry and landing. Another test involved a late power-on of the receiver just before entry to verify the ability of it to quickly collect ephemerides and establish four satellite navigation.

The original flight of three string GPS (no TACANs) was planned for STS-96 in mid 1999. However, GPS certification was delayed for several reasons. First, the start date of TACAN decommissioning slid to the right (Fig. 3), lowering the priority of the GPS upgrade. Second, additional time was required to resolve GPS receiver and shuttle computer software issues encountered during flight and ground testing. Third, the legacy navigation system continued to exhibit excellent performance. 


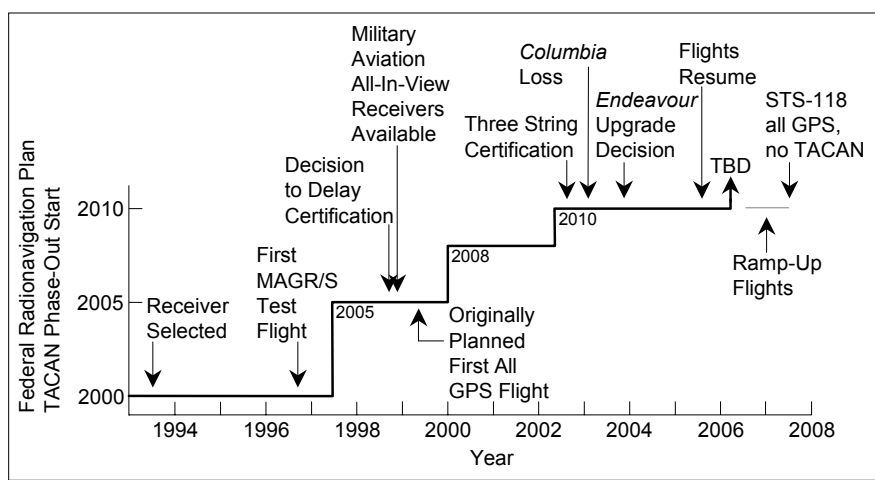

Fig. 3. Timeline of GPS Project events and TACAN phase-out start dates from the Federal Radionavigation Plan.

Additional receiver software versions, laboratory testing and Shuttle test flights were scheduled. Project changes were made to enhance communication between project participants and to improve identification, documentation and resolution of issues. The NASA independent verification and validation contractor audited the receiver software, that had been developed at government expense [3-4].

\section{Contingency Use of GPS before Certification}

During the pre-certification flight test phase (1996 to 2002), flight rules were defined to govern the use of selected MAGR/S state vectors under emergency scenarios, even though the MAGR/S was not yet certified. Those scenarios were:

- Use in place of a voice delta state uplink.

- Low cloud ceilings at landing, on-board and/or ground station TACAN and MLS failures that could result in a high-risk crew bailout and loss of vehicle.

- Resolution by Mission Control of dilemmas between redundant legacy navigation sensors.

\section{E. Three String GPS Certification}

The MAGR/S and associated shuttle computer software was certified for TACAN replacement in August of 2002, over three years after the original target date. On October 23 , 2003, the Shuttle Program approved the removal of the three TACAN units from Endeavour, and the installation of two additional MAGR/S receivers. This brought Endeavour to the three string GPS configuration.

\section{F. Certification of Simultaneous Processing of Single String GPS and TACAN}

After three string certification, it was expected that the Program would continue to fly a mixed fleet of single and three string GPS configured orbiters for some time. The upgrade from single to three string GPS would occur as each orbiter was cycled through the periodic Orbiter Major Modification activity.
In addition to activities to certify three string GPS, work was also performed to certify single string GPS use during entry simultaneous with TACAN. Testing was performed to prove that the legacy navigation system could recover from a GPS outage or an update by a worst case GPS vector that made it through the quality assurance tests and selection filter. Testing also confirmed that GPS state vector processing in the PASS and BFS computers would not interfere with measurements processing from legacy navigation sensors. Monte Carlo runs were executed in a simulation of the shuttle flight software. Testing was also conducted in the Shuttle Avionics Integration Laboratory at the NASA Johnson Space Center, using real shuttle hardware and software.

Test results indicated that there were no ill effects from simultaneous TACAN and GPS processing and that GPS incorporation improved navigation system performance until MLS acquisition. PASS navigation state updates at MLS acquisition were smaller and required trajectory corrections by the crew were reduced during the final approach phase. Use of single string GPS data in conjunction with TACAN was certified for flight in December of 2002.

\section{G. Additional Uses of Single String GPS}

After the three and single string GPS configurations were certified for operational use, additional uses for single string GPS pertaining to launch commit and entry were determined. These further enhanced safety of flight and provided the crew and Mission Control personnel with operational experience and confidence building in GPS before the program replaced TACAN. These additional uses were:

- Use GPS as an extra level of redundancy in case of onboard TACAN failure, TACAN ground station failure, or C Band radar failure.

- Provide redundancy in the event of ground radar tracking station failures.

- Avoid early mission termination due to TACAN failures while on-orbit.

- Provide state vectors to support emergency deorbit if vectors from Mission Control are not available.

- Permit launch in the event of a TACAN failure on the pad.

Emergency shuttle landings could be performed at sites other than the Kennedy Space Center, Edwards Air Force Base, and Northrup Strip. These landings could force the shuttle to use TACAN ground stations that are not calibrated to tighter NASA standards. TACAN biases resulting from use of less stringently calibrated ground stations can result in navigation errors that violate the guidance constraints. TACAN accuracy depends on the orbiter trajectory with respect to the TACAN ground station, the type of approach 
flown (overhead or straight in), the distance of the TACAN ground station from the runway, and the duration of the cone of confusion. Single string GPS provides more accurate and reliable navigation for such landings.

However, a lack of GPS redundancy in the single string configuration prevents the GPS receiver from being used as a sole means of navigation for emergency landings.

\section{H. GPS and the Columbia Accident}

Columbia carried a GPS receiver on its final flight, STS107 (January-February 2003). The receiver was recovered on Friday morning, February 28 (a month after the loss of the vehicle and crew), about 300 yards west of Toledo Bend Reservoir, in eastern Texas. The unit was in relatively good condition and the receiver vendor extracted data from it. This data was supplied to the Columbia investigation team. GPS receiver data from the Columbia entry was used along with other on-board navigation data to reconstruct the entry trajectory and event timeline.

After the loss of Columbia, the Shuttle Program was directed to end flights in 2010. As a result, the Program decided not to upgrade the orbiters Discovery and Atlantis from the single string GPS to the three string GPS configuration. Unlike Endeavour, these orbiters will process GPS single string in parallel with TACAN.

\section{ShUTTLE SingLe STRING GPS RAMP-UP}

\section{A. Ramp-Up Philosophy}

The original circa 1998 plan for introducing GPS navigation to Space Shuttle entry assumed that GPS would be used for the first time on the first all GPS, no TACAN flight. First use of GPS navigation for entry depended only upon the certification of the GPS system on the shuttle. However, when the GPS certification effort was extended and modification of the first vehicle for three string operations was delayed, the operations community elected to implement a ramp-up philosophy in order to gain confidence in and operational experience with the use of GPS during entry. This ramp-up approach involved the phased application of GPS to either PASS or BFS, in parallel with TACAN processing.

\section{B. GPS Incorporation During the Single String Ramp-Up}

The operational single string ramp-up for GPS use during entry occurred over four flights in 2006 and 2007 (Table I) to the International Space Station. These flights were flown by the orbiters Discovery and Atlantis.

GPS incorporation was limited to the BFS for the first flight (STS-121) to keep the PASS navigation software in a nominal state, untouched by GPS (Fig. 4). In the event of a problem with GPS and BFS navigation, the PASS would not be impacted. GPS incorporation began once confirmation of acceptable GPS performance was obtained with ground radar tracking.

The second (STS-115) and third (STS-116) flights incorporated GPS to the PASS only, leaving the BFS in a nominal state. The fourth flight (STS-117) incorporated GPS in both the PASS and BFS. On these flights GPS was incorporated before the deorbit burn, during the deorbit preparation periods from approximately 2.5 hours through 45 minutes before the deorbit burn. GPS was then inhibited until confirmation with ground tracking during entry.

\section{Single String Ramp-Up GPS Flight Performance}

Before the deorbit burn periodic comparisons between the ground tracking solution, based on TDRSS and C-Band tracking data, confirmed good GPS states. Radar tracking during entry also confirmed good GPS performance before GPS data was taken to the PASS and/or BFS.

During all flights GPS performed as expected during entry and was in agreement with the ground radar tracking derived state vector. PASS navigation, BFS navigation, and legacy

TABLE I

GPS RAMP-UP FLIGHTS

\begin{tabular}{|c|c|c|c|c|c|c|c|c|}
\hline \multirow[b]{2}{*}{ Mission } & \multirow[b]{2}{*}{ Orbiter } & \multirow{2}{*}{$\begin{array}{l}\text { Launch/ } \\
\text { Pad }\end{array}$} & \multirow{2}{*}{$\begin{array}{l}\text { Landing/ } \\
\text { Runway }\end{array}$} & \multirow{2}{*}{$\begin{array}{l}\text { Navigation } \\
\text { Configuration }\end{array}$} & \multicolumn{2}{|c|}{ Pre-Deorbit } & \multicolumn{2}{|c|}{ Entry* } \\
\hline & & & & & PASS & BFS & PASS $\dagger$ & $\mathrm{BFS}^{\dagger}$ \\
\hline $\begin{array}{l}\text { STS-121 } \\
\text { ULF1.1 }\end{array}$ & $\begin{array}{l}\text { Discovery } \\
\text { OV-103 }\end{array}$ & $\begin{array}{l}7 / 4 / 06 \\
39 \mathrm{~B}\end{array}$ & $\begin{array}{l}7 / 17 / 06 \\
\text { KSC } 15\end{array}$ & $\begin{array}{l}1 \text { GPS } \\
3 \text { TACANS }\end{array}$ & & & TACAN & $\begin{array}{l}\text { GPS } \\
\text { TACAN }\end{array}$ \\
\hline $\begin{array}{l}\text { STS-115 } \\
12 \mathrm{~A}\end{array}$ & $\begin{array}{l}\text { Atlantis } \\
\text { OV-104 }\end{array}$ & $\begin{array}{l}9 / 9 / 06 \\
39 \mathrm{~B}\end{array}$ & $\begin{array}{l}9 / 21 / 06 \\
\text { KSC } 33\end{array}$ & $\begin{array}{l}1 \text { GPS } \\
3 \text { TACANS }\end{array}$ & GPS & & $\begin{array}{l}\text { GPS } \\
\text { TACAN }\end{array}$ & TACAN \\
\hline $\begin{array}{l}\text { STS-116 } \\
\text { 12A.1 }\end{array}$ & $\begin{array}{l}\text { Discovery } \\
\text { OV-103 }\end{array}$ & $\begin{array}{l}12 / 9 / 06 \\
39 \mathrm{~B}\end{array}$ & $\begin{array}{l}12 / 22 / 06 \\
\text { KSC } 15\end{array}$ & $\begin{array}{l}1 \text { GPS } \\
3 \text { TACANS }\end{array}$ & GPS & & $\begin{array}{l}\text { GPS } \\
\text { TACAN }\end{array}$ & TACAN \\
\hline $\begin{array}{l}\text { STS-117 } \\
13 \mathrm{~A}\end{array}$ & $\begin{array}{l}\text { Atlantis } \\
\text { OV-104 }\end{array}$ & $\begin{array}{l}6 / 8 / 07 \\
39 \mathrm{~A}\end{array}$ & $\begin{array}{l}\text { 6/22/07 } \\
\text { EDW } 22\end{array}$ & $\begin{array}{l}1 \text { GPS } \\
3 \text { TACANS }\end{array}$ & GPS & GPS & $\begin{array}{l}\text { GPS } \\
\text { TACAN }\end{array}$ & $\begin{array}{l}\text { GPS } \\
\text { TACAN }\end{array}$ \\
\hline $\begin{array}{l}\text { STS-118 } \\
\text { 13A.1 }\end{array}$ & $\begin{array}{l}\text { Endeavour } \\
\text { OV-105 }\end{array}$ & $\begin{array}{l}8 / 8 / 07 \\
39 \mathrm{~A}\end{array}$ & $\begin{array}{l}8 / 21 / 07 \\
\text { KSC } 15\end{array}$ & 3 GPS & GPS & & GPS & $\begin{array}{l}\text { PASS } \rightarrow \text { BFS } \\
\text { state vector } \\
\text { transfers }\end{array}$ \\
\hline
\end{tabular}

* GPS is incorporated during entry after confirmation with ground radar.

$\dagger$ PASS and BFS also incorporate drag altitude and barometric altimeter measurements.

$\$$ PASS incorporates GPS until MLS acquisition. If MLS is not available, GPS incorporation stops at $500 \mathrm{ft}$. 


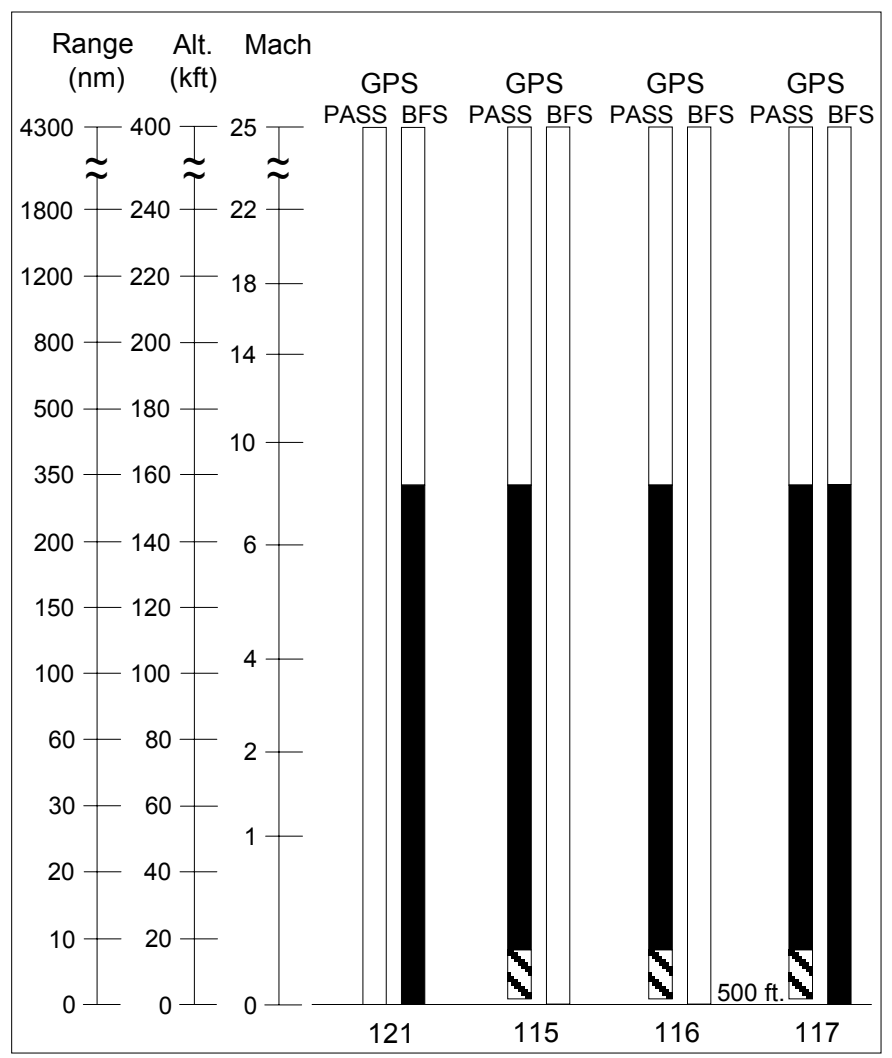

Fig. 4. GPS incorporation for the single string GPS ramp-up flights.

sensor performance (TACAN, IMU, air data, MLS) was also as expected.

Additional analysis of GPS and integrated navigation system performance was performed after each mission. A Best Estimate of Trajectory (BET) was generated using both ground and onboard navigation sources, including ground tracking, IMU, and MLS data. The BET is used for evaluating the performance of PASS and BFS navigation. All the available data is processed using a forward pass Kalman filter and a backward smoother. Quality Assurance test and receiver tracking performance was also examined.

\section{STS-116 GPS Flight Results}

The following is a discussion of flight results for the STS116 single string GPS flight. The entry and landing of Discovery occurred on December 22, 2006 with a landing on Kennedy Space Center runway 15 . The first deorbit opportunity was waived off due to a weather concern.

Before the deorbit burn GPS was processed in the PASS for just over 155 minutes. The one revolution delay in performing the deorbit burn resulted in a longer period of pre-deorbit burn GPS processing than was performed on STS- 115 . Periodic comparisons between the ground tracking solution, based on TDRSS and C-Band tracking data, confirmed good GPS states during this timeframe. Deorbit occurred on the second opportunity resulting in an approach to KSC 15 from the westerly direction (Fig. 5 and 6).
Receiver performance during entry is illustrated by three receiver parameters plotted in Fig. 7. Figure of Merit (FOM) is the GPS receiver estimate of the accuracy of the GPS position vector. Geometric Dilution of Precision (GDOP) is a measure of how well the geometry of the tracked GPS satellites will enable the receiver to resolve position errors. Normally the receiver tracks 4 satellites for navigation measurements. The less that 4 satellite tracking flag (bottom plot in Fig. 7) is set to a value of one if less than 4 satellites are tracked.

During the entry plasma region, the number of satellites available to track is reduced due to the ionizing effects of the plasma. This results in higher FOM and GDOP values, called chimneys. The number of satellites tracked will vary from four to zero. During the plasma region, which ranged from an altitude of $271,000 \mathrm{ft}$ to $225,000 \mathrm{ft}$, a FOM chimney (FOM > 5 ) was experienced with a duration much longer than those typically observed on previous shuttle missions (Fig. 7).

The FOM chimney caused the GPS state vector to fail a QA test, therefore it was not a candidate for incorporation into the PASS navigation software. The chimney duration was 13 minutes and 10 seconds and ended at an altitude of 173,000 $\mathrm{ft}$. Analysis indicated that two factors contributed to the chimney, neither of which was due to plasma. The line-ofsight vectors to two of the satellites were very close, resulting in poor satellite geometry. One of the satellites had been recently activated and not yet moved to its final orbital location. Additionally, there were repeated unsuccessful attempts to acquire a satellite that was blocked by the shuttle wing. FOM chimneys are not normally seen this late in the entry. However, the chimney ended and a GPS state vector was again available for selection before a PASS navigation state update was required to ensure adequate vehicle performance.

Navigation state vector accuracy during entry is illustrated on plots comparing the PASS and BFS position vectors to the post-flight BET (Fig. 8 to Fig. 10). State vector differences between the vectors are in an Earth-relative frame, centered on the spacecraft, and expressed in the radial (U), in-track $(\mathrm{V})$, and cross-track (W) directions.

TACAN data was incorporated in the PASS at an altitude of 147,000 ft. TACAN processing decreased the downtrack position error in the navigation state to low values, as expected (Fig. 8). A residual error was left in the radial and crosstrack directions. During the initial processing timeframe, TACAN is not as effective in the radial and crosstrack directions.

GPS was incorporated in the PASS at an altitude of 137,000 $\mathrm{ft}$ (Fig. 8). At the time of GPS incorporation, the remaining $4,000 \mathrm{ft}$ of radial and 2,000 ft of crosstrack error in the navigation state was corrected. Fig. 9 shows the BET and PASS comparisons from $130,000 \mathrm{ft}$ to touchdown; the sawtooth pattern indicating the update of the navigation state with GPS is apparent. There were no QA test failures during GPS incorporation. 


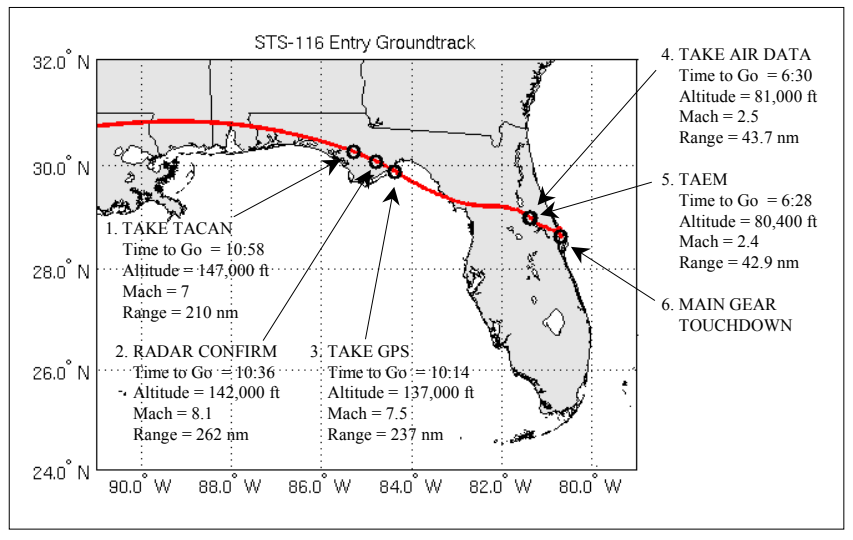

Fig. 5. STS-116 entry ground track.

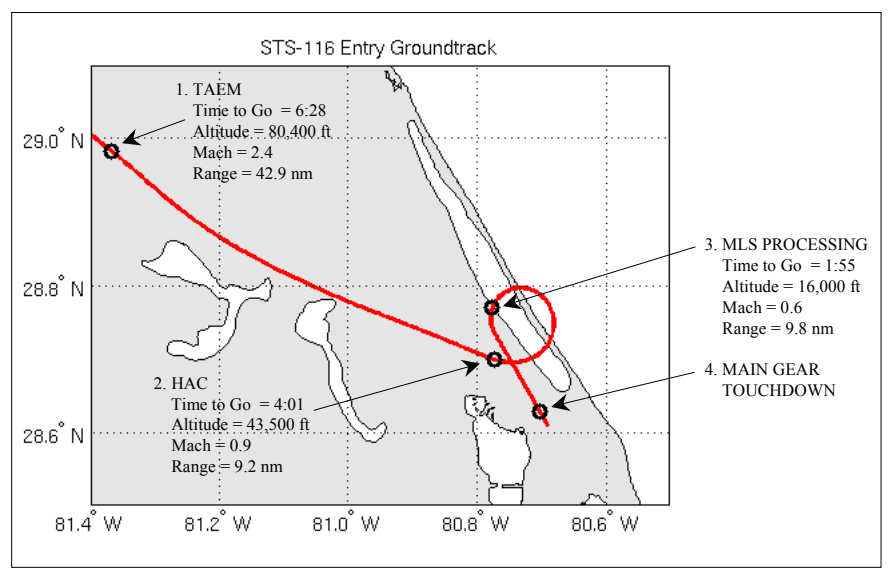

Fig. 6. STS-116 approach and landing ground track.
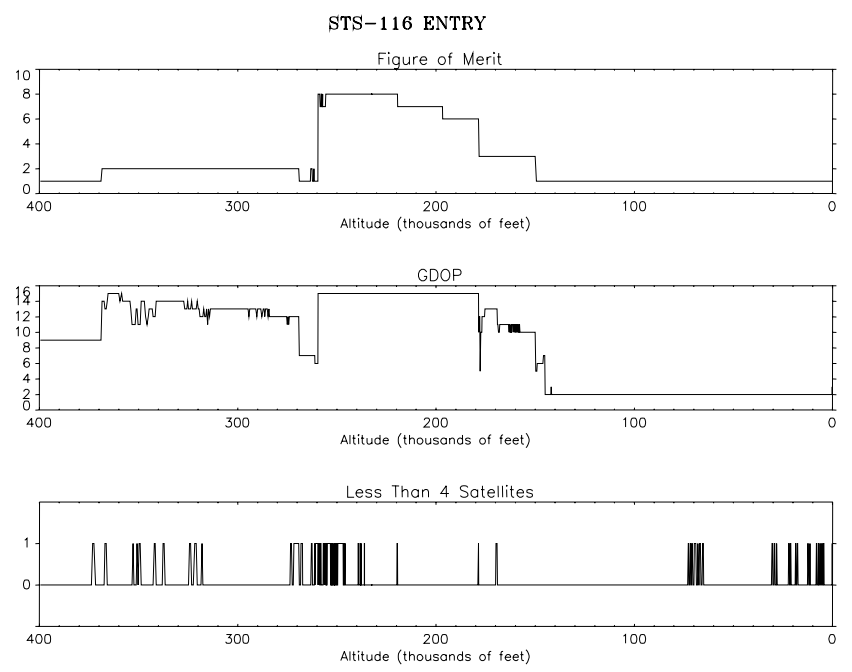

Fig. 7. STS-116 receiver performance parameters.
STS-116 Entry BET minus PASS

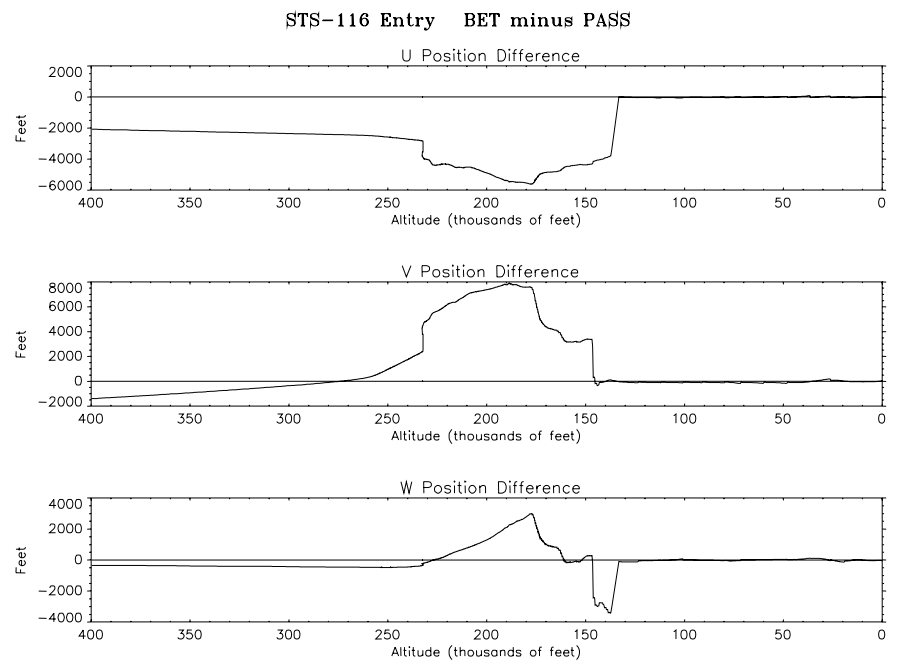

Fig. 8. STS-116 BET versus PASS position vector compare.

STS-116 Entry BET minus PASS
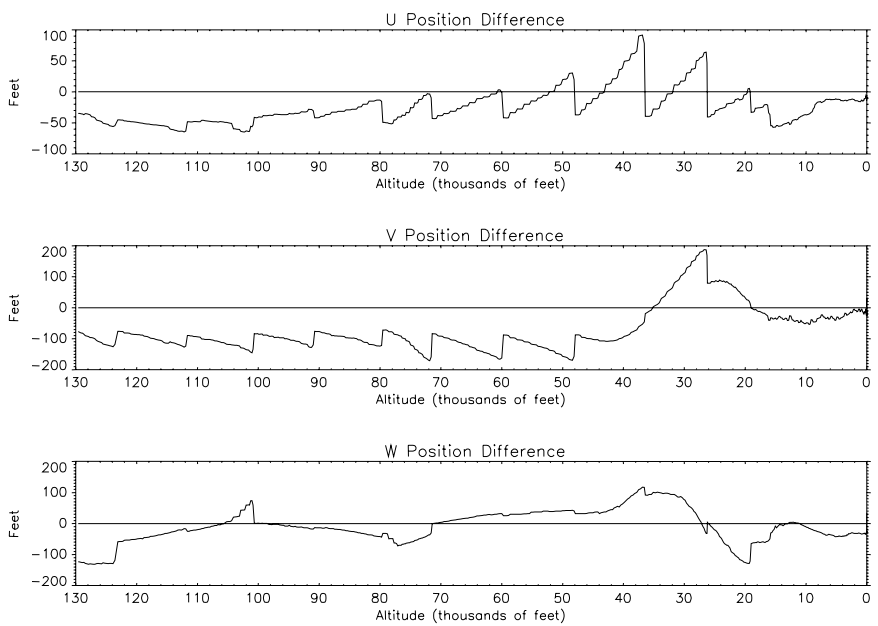

Fig. 9. STS-116 BET versus PASS position vector compare.
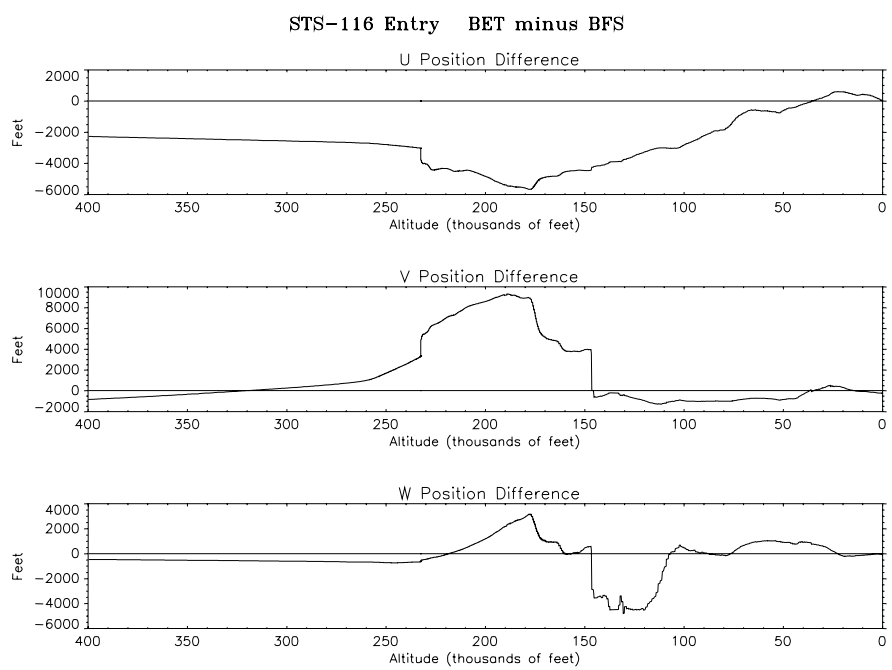

Fig. 10. STS-116 BET versus BFS position vector compare. 
Fig. 10 is a comparison of the BFS navigation state with the BET from 400,000 $\mathrm{ft}$ to landing. BFS incorporated legacy navigation data (IMU, TACAN, air data) but no GPS data.

\section{STS-118 FLIGHT RESULTS}

\section{A. GPS Navigation Objective}

The STS-118 mission of Endeavour was the 34th flight of the MAGR/S on the Shuttle fleet and was the first flight with three GPS receivers and no TACANs. The ramp-up objective for STS-118 was to incorporate three string GPS into the PASS and to maintain the BFS navigation state accuracy within acceptable limits with periodic state vector transfers from the PASS.

\section{B. Orbit GPS Performance Evaluation before Entry}

Single string missions used the antenna locations for GPS receiver number 2 on the top and bottom of the crew cabin (Fig. 2). However, the GPS antennas for receivers \#1 and \#3 on Endeavour are in the former TACAN antenna locations. STS-118 was the first flight that would provide GPS performance data for GPS antennas located in the legacy TACAN antenna locations.

The standard configuration for the three string GPS receivers during the orbit phase of a mission is only one receiver powered on. This configuration lowers the power requirement while still providing GPS state vectors from a single receiver. However, since STS-118 was the first threestring flight, the receivers remained powered for the entire flight in order to observe the following:

- The FOM distribution for receivers \#1 and \#3.

- The antenna gain pattern for receivers \#1 and \#3.

- The GPS state vector quality assurance tests and vector selection with three receivers.

The FOM distribution analysis was intended to determine if the FOM performance for receivers \#1 and \#3 would be similar to that of receiver \#2. GPS hardware-in-the-loop certification simulations performed in the Avionics Development Lab (ADL) indicated that performance of receivers \#1 and \#3 would be slightly worse than receiver \#2. Data from all three receivers were recorded from GPS power up before launch through docking with the ISS and from undocking through GPS power-down after landing. The performance of all three receivers was determined to meet entry navigation accuracy requirements.

On-orbit GPS data from a single string GPS flight was used to determine the gain patterns for the receiver \#2 upper and lower antennas. Receiver \#1 and \#3 upper and lower antenna gain patterns were extrapolated from the receiver \#2 patterns. The gain patterns were used in the ADL simulations performed during the certification effort. As with the FOM distribution analysis, data was examined on STS-118 during the orbit phase to determine if the actual receiver \#1 and \#3 performance matched the predicted performance from the ADL. Data was gathered during a 21.5 hour time period following undocking from the International Space Station.

The receiver \#1 upper antenna pre-amp and the receiver \#3 lower antenna pre-amp were powered off. This enabled GPS personnel to determine the gain patterns for the receiver \#1 lower antenna and the receiver \#3 upper antenna. Since the receiver \#1 and receiver \#3 antenna configurations are symmetrical, the antenna gain patterns for all four antennas associated with receivers \#1 and \#3 could be determined. The data indicated that the antennas performed as expected and in most cases better than expected. This confirmed the validity of the receiver \#1 and \#3 antenna patterns used in ADL testing for GPS certification.

The performance of the QA tests and GPS state vector selection was also examined during the on-orbit phase of the flight. Performance was as expected.

\section{Entry Navigation Performance}

The entry of Endeavour occurred on August 21, 2007 with a landing at Kennedy Space Center on runway 15.

GPS was processed before the deorbit burn for just over 79 minutes. Periodic comparisons between the ground tracking solution, based on TDRSS and C-Band tracking data, confirmed good GPS states during this timeframe. The deorbit occurred on the first opportunity resulting in an approach to KSC from the southerly direction (Fig. 11, 12).

GPS tracking performance did degrade during the plasma region, as expected. Plasma effects were observed from approximately $268,000 \mathrm{ft}$ to approximately $210,000 \mathrm{ft}$. There were failures of the receiver to receiver state vector compare QA test during this period, but these failures did not impact navigation performance or subsequent use of GPS data. Plasma effects disappeared and receiver tracking performance returned to nominal well before GPS was processed in the PASS.

GPS processing in the PASS began at an altitude of $138,600 \mathrm{ft}$. after confirmation with ground radar tracking. Fig. 13 and 14 show the BET and PASS comparisons, from $400,000 \mathrm{ft}$ to touchdown and $130,000 \mathrm{ft}$ to touchdown, respectively. As can be seen from the plots, the PASS compared very well to the BET following the incorporation of GPS. The saw-tooth pattern indicates the update of the PASS state with a GPS selected state. There were no QA test failures during GPS incorporation.

MLS processing began at an altitude of 22,000 $\mathrm{ft}$. MLS processing had little impact on the PASS navigation state due to the previous incorporation of GPS. As compared to the post-flight BET, PASS navigation position errors before MLS incorporation were $-36 \mathrm{ft}$ radial, $-104 \mathrm{ft}$ down-track, and $66 \mathrm{ft}$ in cross-track. PASS position errors after one cycle of MLS data had been incorporated were $-1 \mathrm{ft}$ radial, $-103 \mathrm{ft}$ downtrack, and $56 \mathrm{ft}$ in cross-track. 


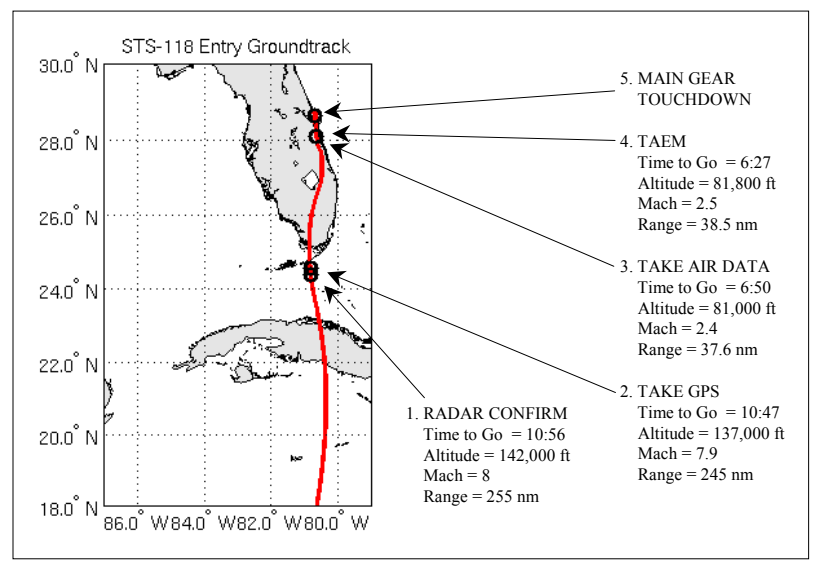

Fig. 11. STS-118 entry ground track.

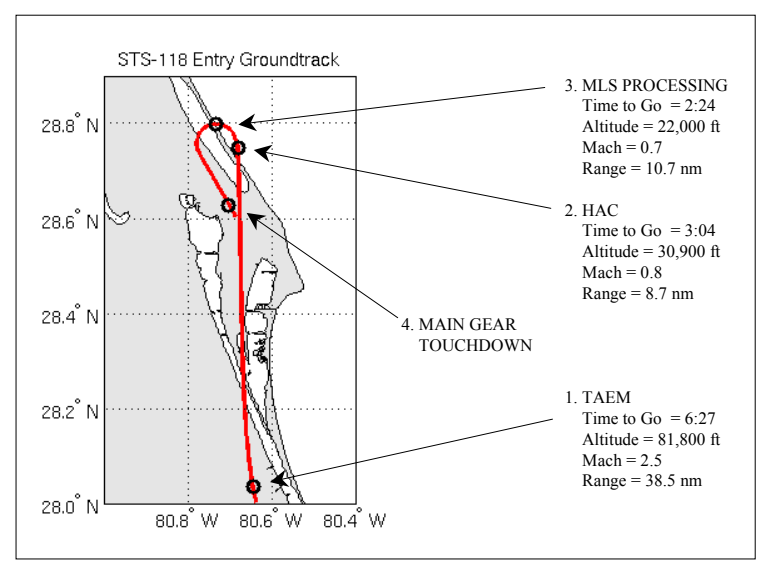

Fig. 12. STS-118 approach and landing ground track.
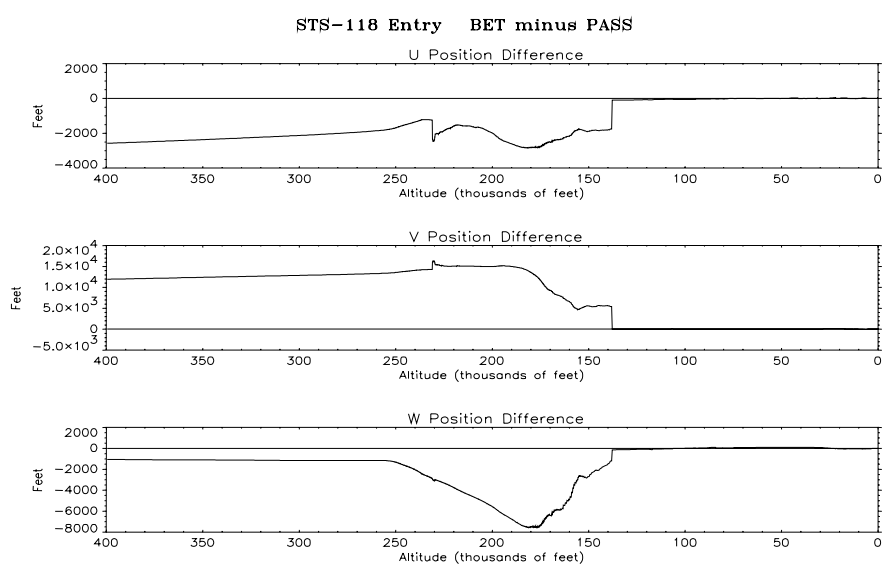

Fig. 13. STS-118 BET versus PASS position vector compare.

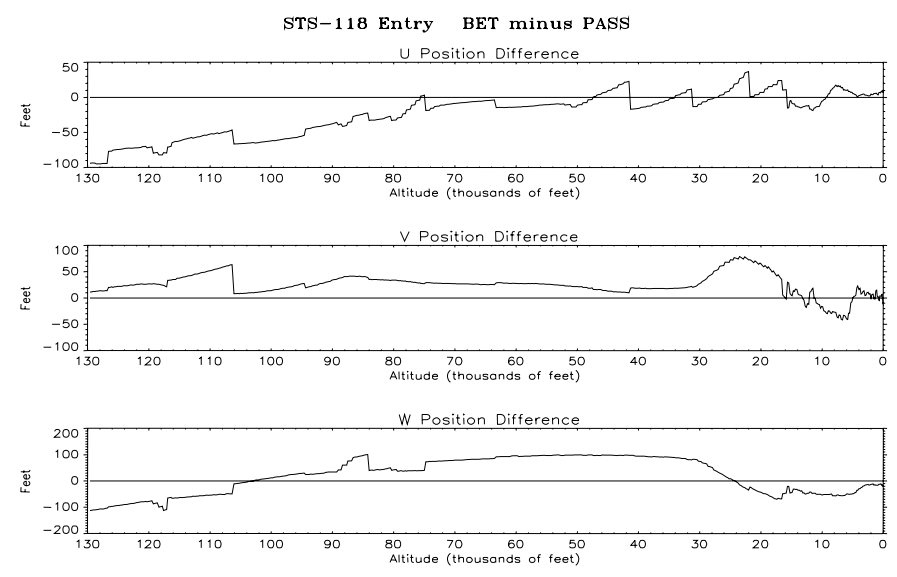

Fig. 14. STS-118 BET versus PASS position vector compare.

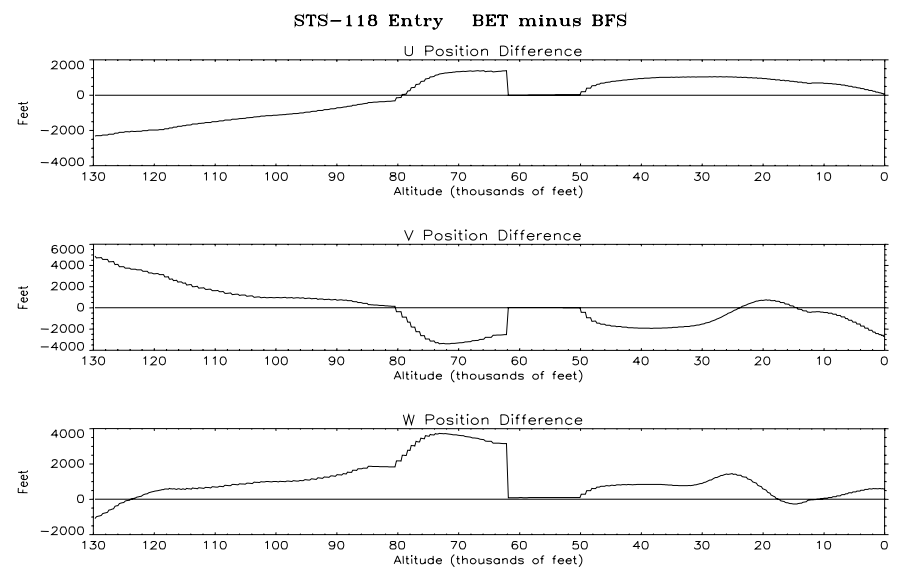

Fig. 15. STS-118 BET versus BFS position vector compare.

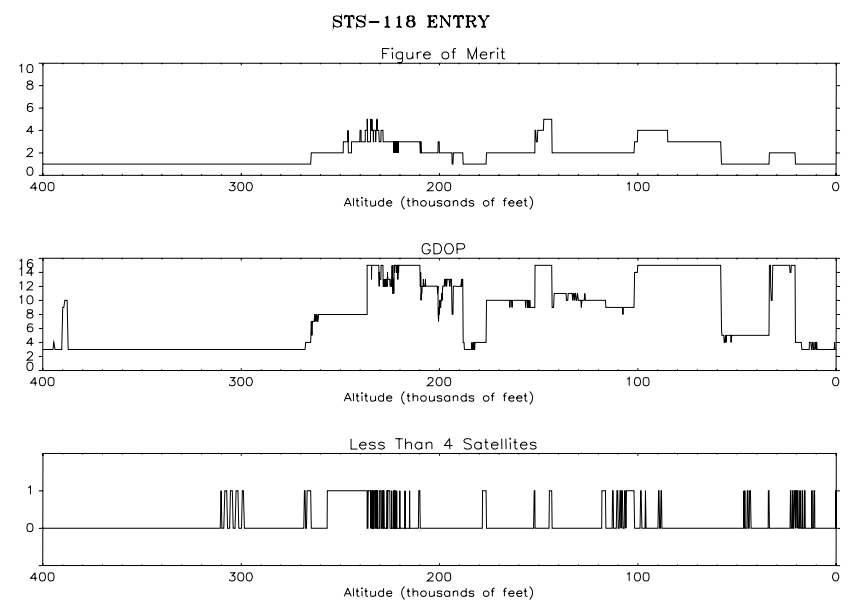

Fig. 16. STS-118 receiver 1 performance parameters. 


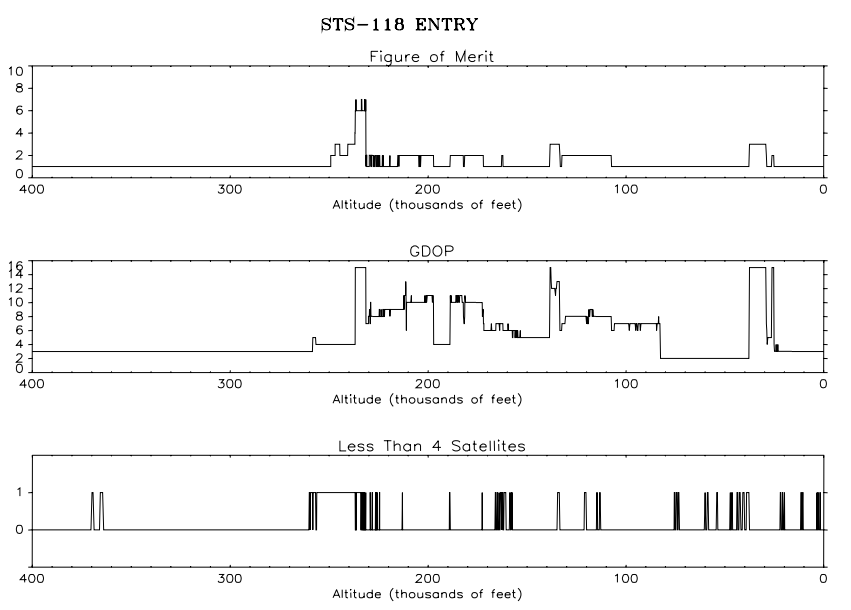

Fig. 17. STS-118 receiver 2 performance parameters.

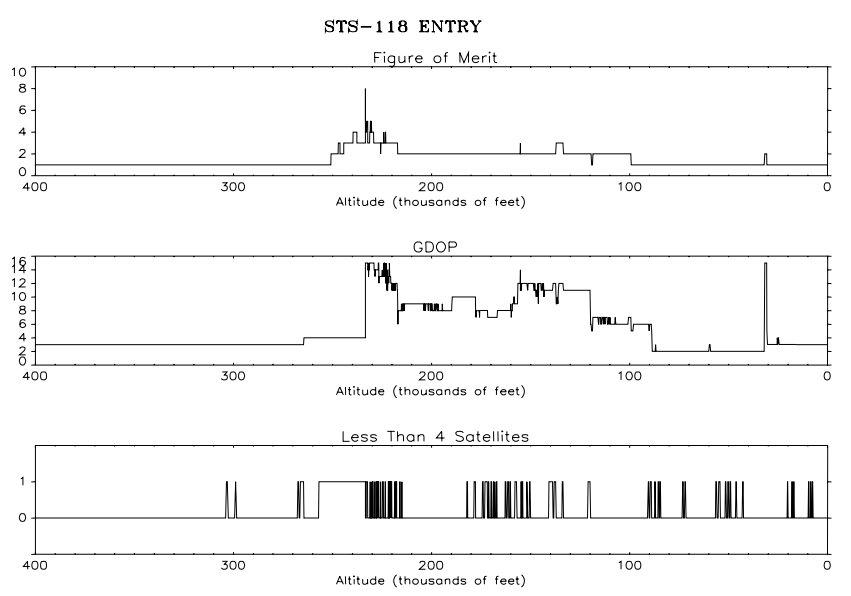

Fig. 18. STS-118 receiver 3 performance parameters.

Air data measurements resulted in larger updates to the BFS state vector than are typically seen. This was due to not incorporating TACAN or GPS directly in the BFS navigation state. Per the ramp-up plan, the BFS state was managed with periodic state vector transfers from the PASS to the BFS. It was expected that one or two state vectors transfers would be required during entry to maintain acceptable BFS navigation state accuracy. During the STS-118 entry, only a single transfer at an altitude of $62,600 \mathrm{ft}$ was performed. Fig. 15 shows the BET and BFS comparisons and clearly shows the transfer at $62,600 \mathrm{ft}$. Since neither GPS nor TACAN data was incorporated in the BFS, the BFS state began to degrade soon after the state vector transfer from the PASS. However, the accuracy of BFS state following the transfer remained within the required limits and a second transfer was not required.

Receiver performance is in Fig. 16, 17, and 18. Each receiver uses a different pair of antennas with different boresights (Fig. 2). FOM, GDOP, and number of satellites tracked by all three receivers varied during entry. State vectors from all three GPS receivers were generally within $100 \mathrm{ft}$ of the ground radar tracking solution in the radial, down-track, and cross-track directions.

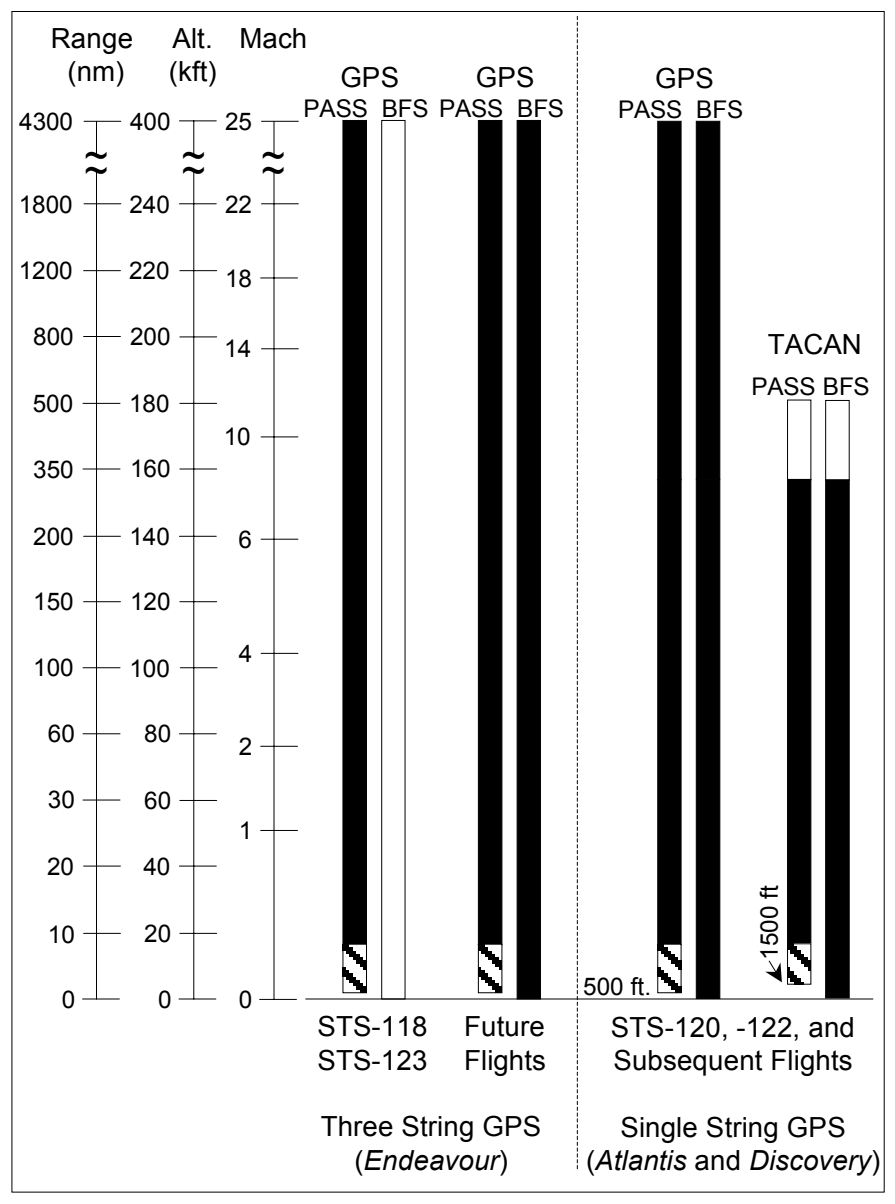

Fig. 19. GPS and TACAN incorporation after the ramp-up flights.

\section{STATE Vector MANAGEMENT ON FUtURE SHUTTLE FLIGHTS}

STS-123 is the next scheduled flight for Endeavour and will be the second three-string GPS flight. The PASS and BFS navigation states for STS-123 will be managed in the same manner as on STS-118. GPS updates will be incorporated into the PASS and state vector transfers from the PASS to the BFS will maintain an acceptable level of BFS navigation accuracy. The current operational plan for the third flight of three-string GPS, currently manifested for STS-126, is for GPS to be taken to both the PASS and BFS. This will eliminate the need for state vector transfers from the PASS to BFS (Fig. 19).

Nominal GPS procedures following ramp-up, for both single string and three string flights, will entail processing GPS in both the PASS and BFS from confirmation with ground tracking through landing. GPS will also be processed on-orbit before the deorbit burn. The legacy navigation aids, drag altitude, TACAN (for single string flights), air data, and MLS will continue to be processed during the entry and landing phases. 


\section{SUMMARY}

The Space Shuttle Program has successfully integrated, flight proven, and certified GPS navigation into the Space Shuttle avionics system as a TACAN replacement. The integration architecture permitted flight testing of the GPS receiver and associated shuttle flight computer software without requiring the use of GPS for entry navigation. In addition, the GPS integration was performed in a manner that did not compromise the integrity of the legacy entry navigation system.

Due to the impending retirement of the Shuttle fleet in 2010, only the orbiter Endeavour is equipped with three GPS receivers and no TACANs. Discovery and Atlantis will continue to use three TACAN units in conjunction with one GPS receiver. Single string GPS provides the Space Shuttle with several benefits. These benefits are:

- An extra level of redundancy in the event of a TACAN failure.

- Additional redundancy in the event of a ground radar failure during entry.

- Avoiding early mission termination due to TACAN failures while on-orbit.

- More accurate and reliable navigation for landings at sites with no ground radar or sites that have TACAN ground stations of questionable calibration.

- A source of state vectors to support autonomous emergency deorbit and landing.

Many important technical and process lessons were learned during the extended flight test program. These lessons are being applied to navigation development for the next NASA human spacecraft, Orion.

\section{REFERENCES}

[1] P. M. Kachmar, W. Chu, P. Neirinckx, and M. Montez, "U.S. Space Shuttle Integrated GPS Navigation Capability," Proceedings of the Institute of Navigation GPS 93 Conference, Institute of Navigation, Fairfax, VA, 1993, pp. 313-326.

[2] J. L. Goodman, "Space Shuttle Navigation in the GPS Era," Proceedings of the Institute of Navigation National Technical Meeting, Institute of Navigation, Fairfax, VA, 2001.

[3] J. L. Goodman, GPS Lessons Learned From The ISS, Space Shuttle and $X-38$, NASA Contractor Report NASA/CR-2005-213693, NASA Johnson Space Center, November 2005. See the NASA Technical Reports server at http://ntrs.nasa.gov/. Accessed February 25, 2008.

[4] J. L. Goodman, Lessons Learned From Seven Space Shuttle Missions, NASA Contractor Report NASA/CR-2007-213697, NASA Johnson Space Center, January 2007. See the NASA Technical Reports server at http://ntrs.nasa.gov/. Accessed February 25, 2008.

[5] J. L. Goodman, H. R. Mamich, and D. W. Saley, "Orion On-Board Navigation Architecture and Operations Concepts," Guidance and Control 2008, Advances in the Astronautical Sciences, Univelt, San Diego, CA, 2008.

[6] S. Gomez, Three Years of Global Positioning System Experience on International Space Station, NASA Technical Publication NASA/TP-2006-213168, NASA Johnson Space Center, August 2006. See the NASA Technical Reports server at http://ntrs.nasa.gov/. Accessed February 25, 2008.

[7] J. L. Goodman, J. P. Brazzel, and D. A. Chart, "Challenges of Orion Rendezvous Development," 2007 AIAA Guidance, Navigation and Control Conference, AIAA, Reston, VA, 2007. 


\title{
Operational Use of GPS Navigation for Space Shuttle Entry
}

\author{
John L. Goodman \\ Carolyn A. Propst
}

United Space Alliance, LLC

IEEE/ION PLANS 2008

May 5-8, 2008

Monterey, California

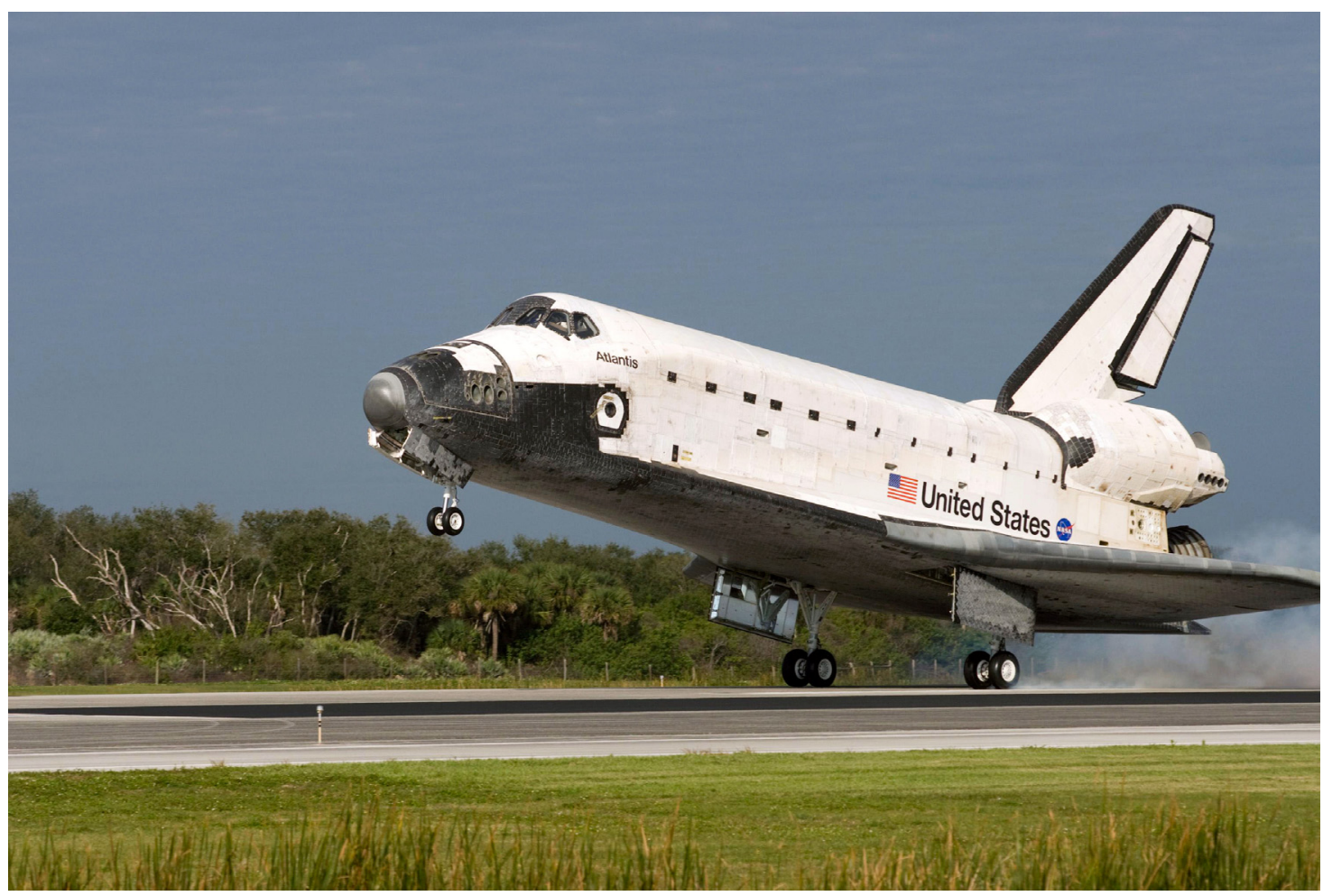

Copyright $@ 2008$ by United Space Alliance, LLC. Published by the IEEE and ION with permission. These materials are sponsored by the National Aeronautics and Space Administration under Contract NNJ06VA01C. The U.S. Government retains a paid-up, nonexclusive, irrevocable worldwide license in such materials to reproduce, prepare derivative works, distribute copies to the public, and perform publicly and display publicly, by or on behalf of the U.S. Government. All other rights are reserved by the copyright owners. 

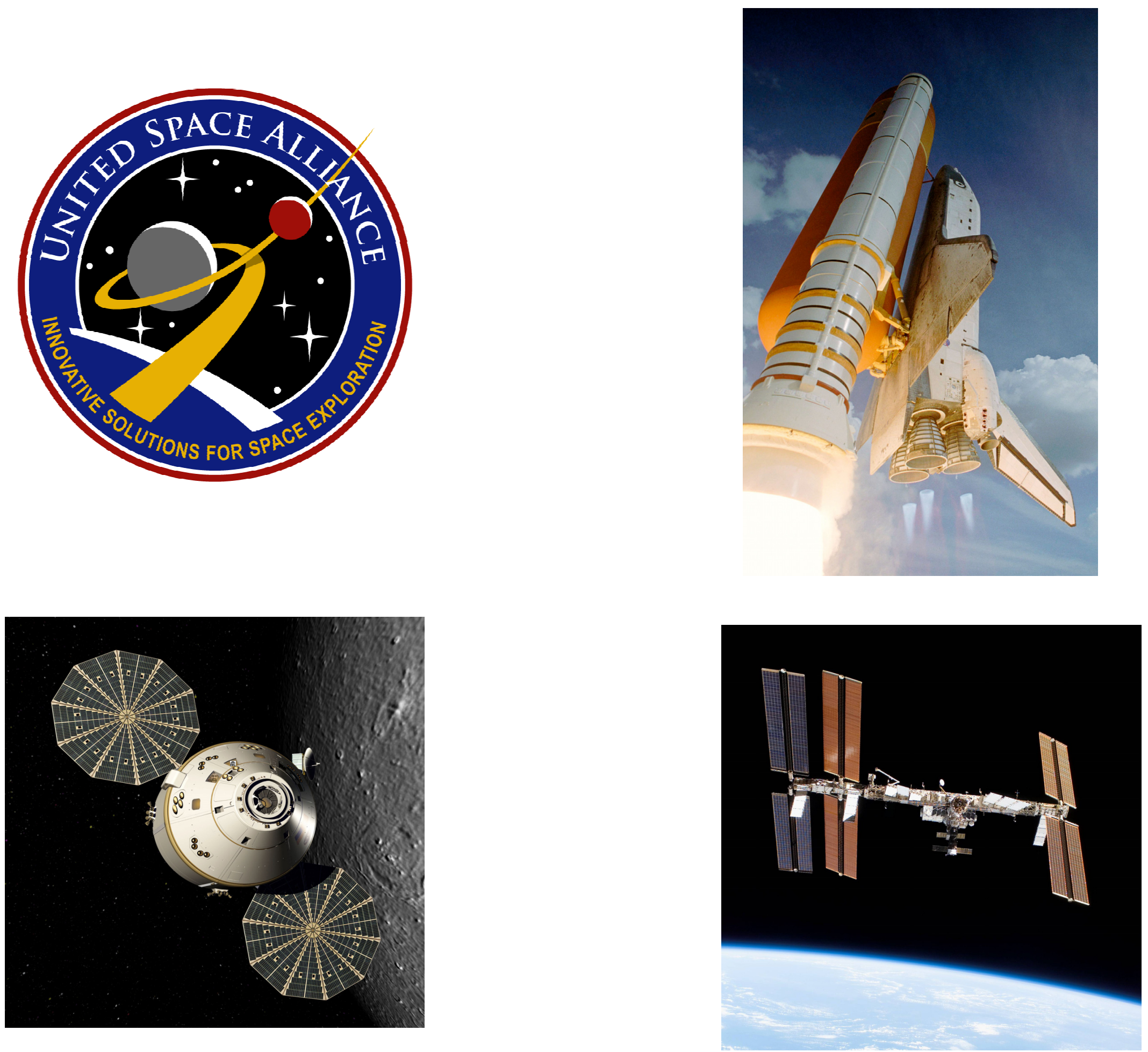


\section{Agenda}

Entry Navigation for Mercury, Gemini, and Apollo

Shuttle Entry Navigation

Requirement for Shuttle GPS

Integration Architecture

Shuttle GPS Flight Tests

Ramp-Up for Using GPS During Entry

Ramp-Up Flight Results

Lessons Learned 


\section{IMU Only Entry Nav For Mercury, Gemini, and Apollo}

Mercury - Ballistic entry

Directional and vertical gyros $0.05 \mathrm{~g}$ accelerometer switch

Gemini - Lifting or Ballistic entry Flight computer Stable member IMU Backup Rate Gyros
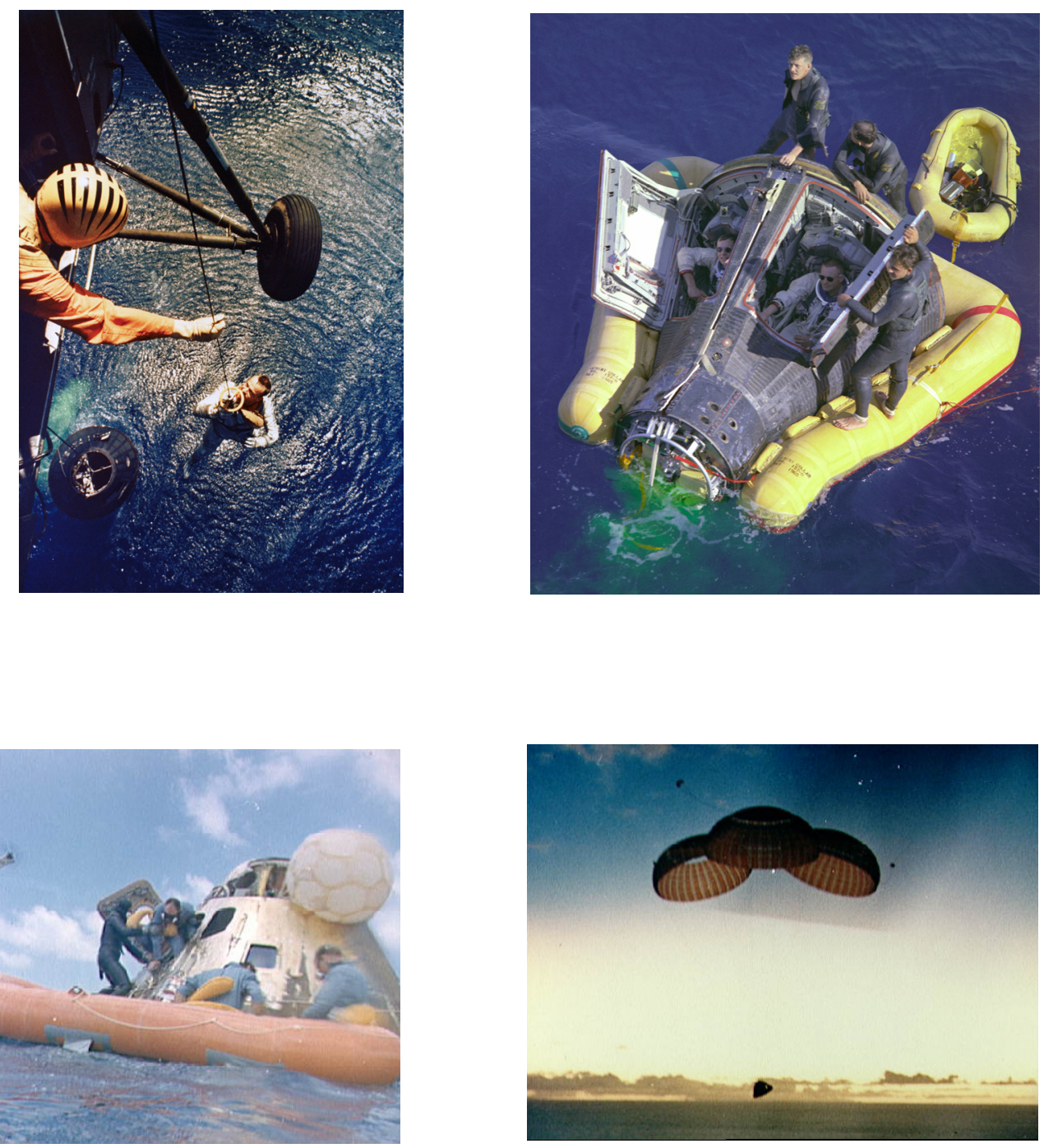


\section{Shuttle Required a More Complex Entry Nav System}

Unpowered runway landings.

Larger cross-range capability.

Tighter thermal, aero, and structural constraints.

Statically unstable in pitch and yaw.

Use of aero-surfaces along with RCS jets.

Four primary flight computers.

One backup flight computer.

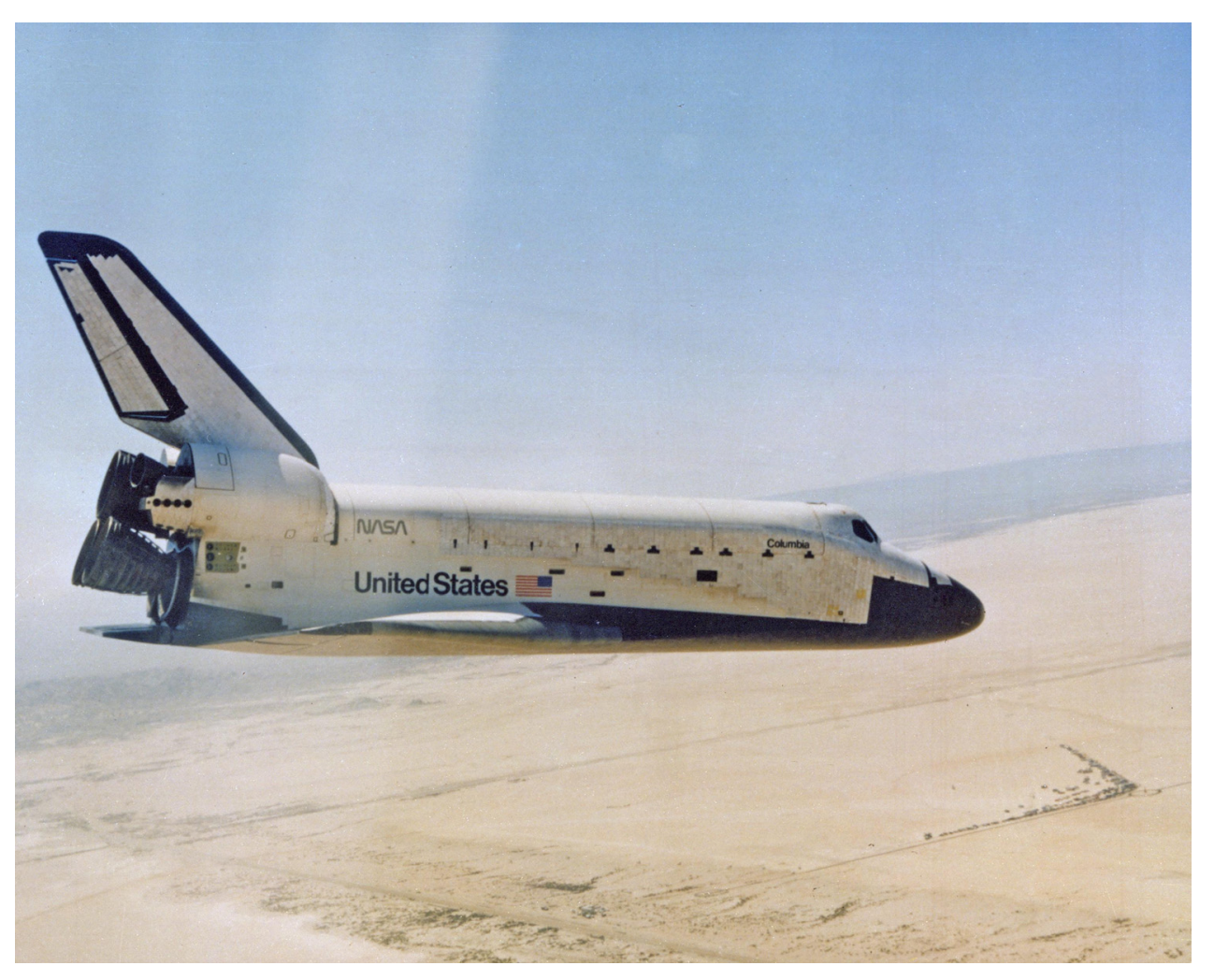




\section{Shuttle entry nav requires more sensors than IMUs.}

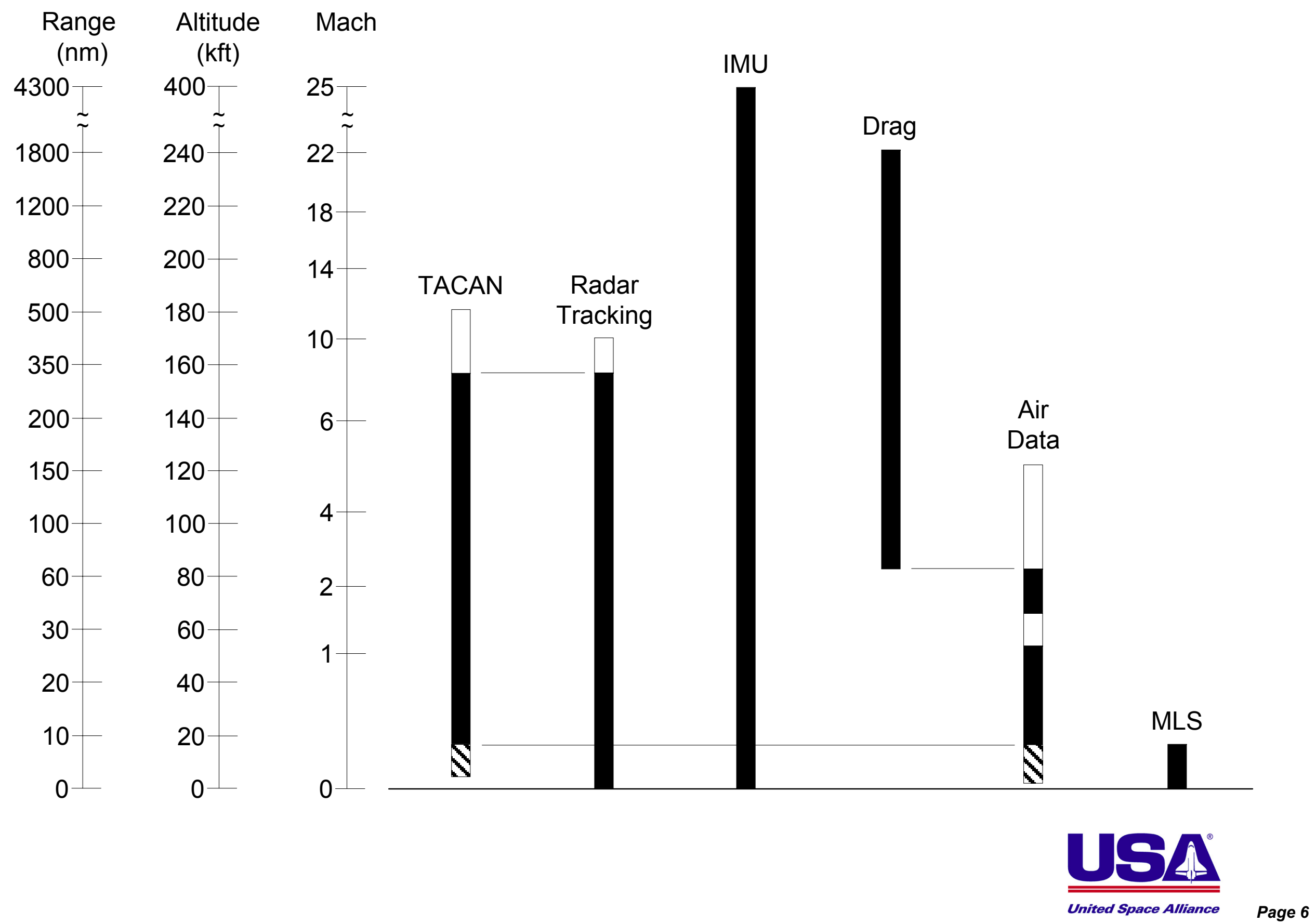




\section{By 1993, TACAN phase-out was scheduled to begin}

in the year 2000.

In 1993 the Shuttle Program selected an in-production military aviation receiver.

Shuttle GPS was scheduled to be certified in early 1999 .

First flight with three GPS receivers and no TACAN units was scheduled for mid-1999.

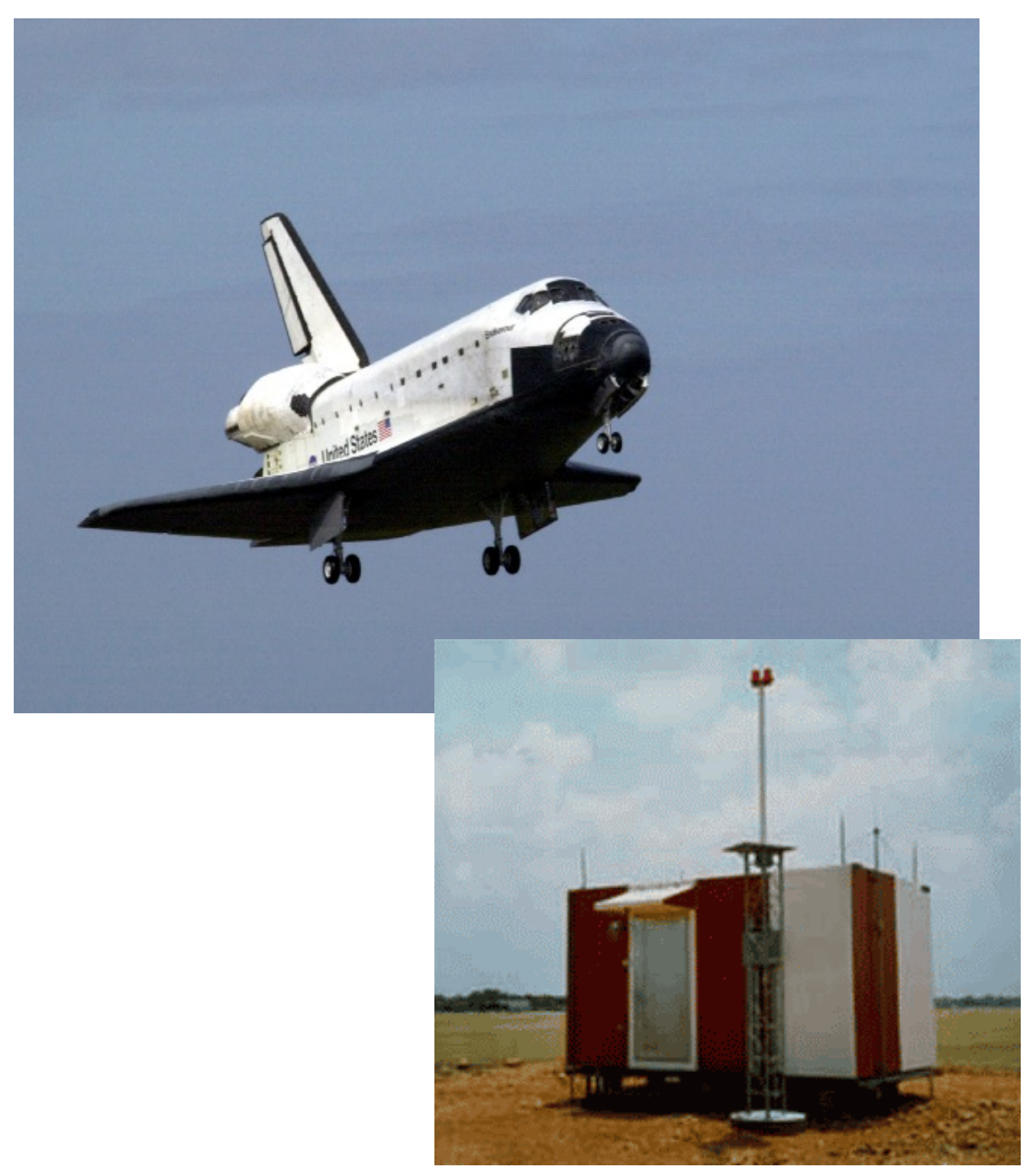




\section{What does the Space Shuttle use GPS for?}

TACAN replacement during entry.

GPS is available on-orbit if it is needed.

GPS does not perform precision orbit determination.

GPS is not used for rendezvous

GPS is not used for precision landing. 


\section{Why does the Space Shuttle have a 5 channel GPS receiver?}

In 1993 all-in-view military aviation receivers were not available.

They did become available in 1998, two years before TACAN phase-out was scheduled to begin. 


\section{Will the Space Shuttle be upgraded with an all-in-view GPS receiver?}

No. The Shuttle Program will stop flying in 2010.

Current navigation system performance with a 5 channel receiver is acceptable. 


\section{Shuttle entry nav performance has been excellent since the first flight in 1981.}

GPS was integrated as a separate navigation system to avoid changes to the flight proven legacy system.

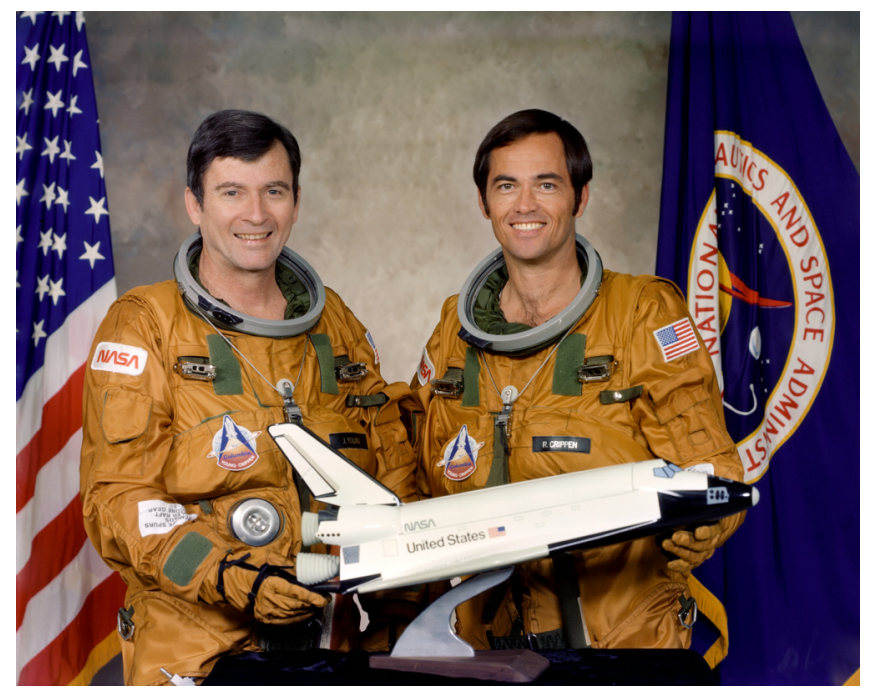

Shuttle GPS could be tested over an entire Shuttle mission without having to use GPS data for navigation.

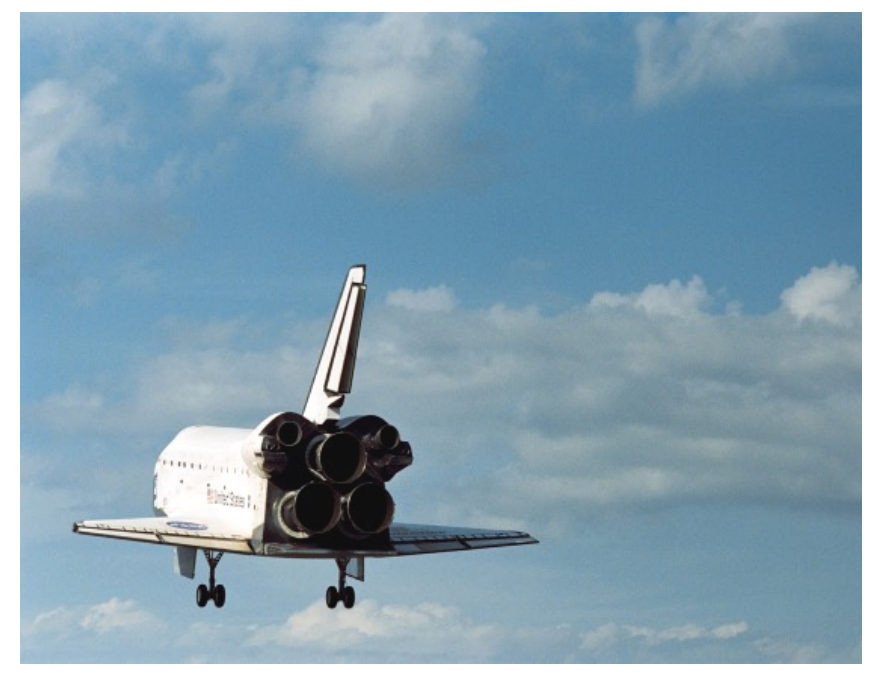


Between September 1996 and June 2002 there were 25 Shuttle missions that flew GPS in support of certification.

Extensive flight testing allowed complex software issues to be discovered and resolved.

GPS was certified for use during missions in August of 2002.

The first all GPS, no TACAN flight was flown in August of 2007.

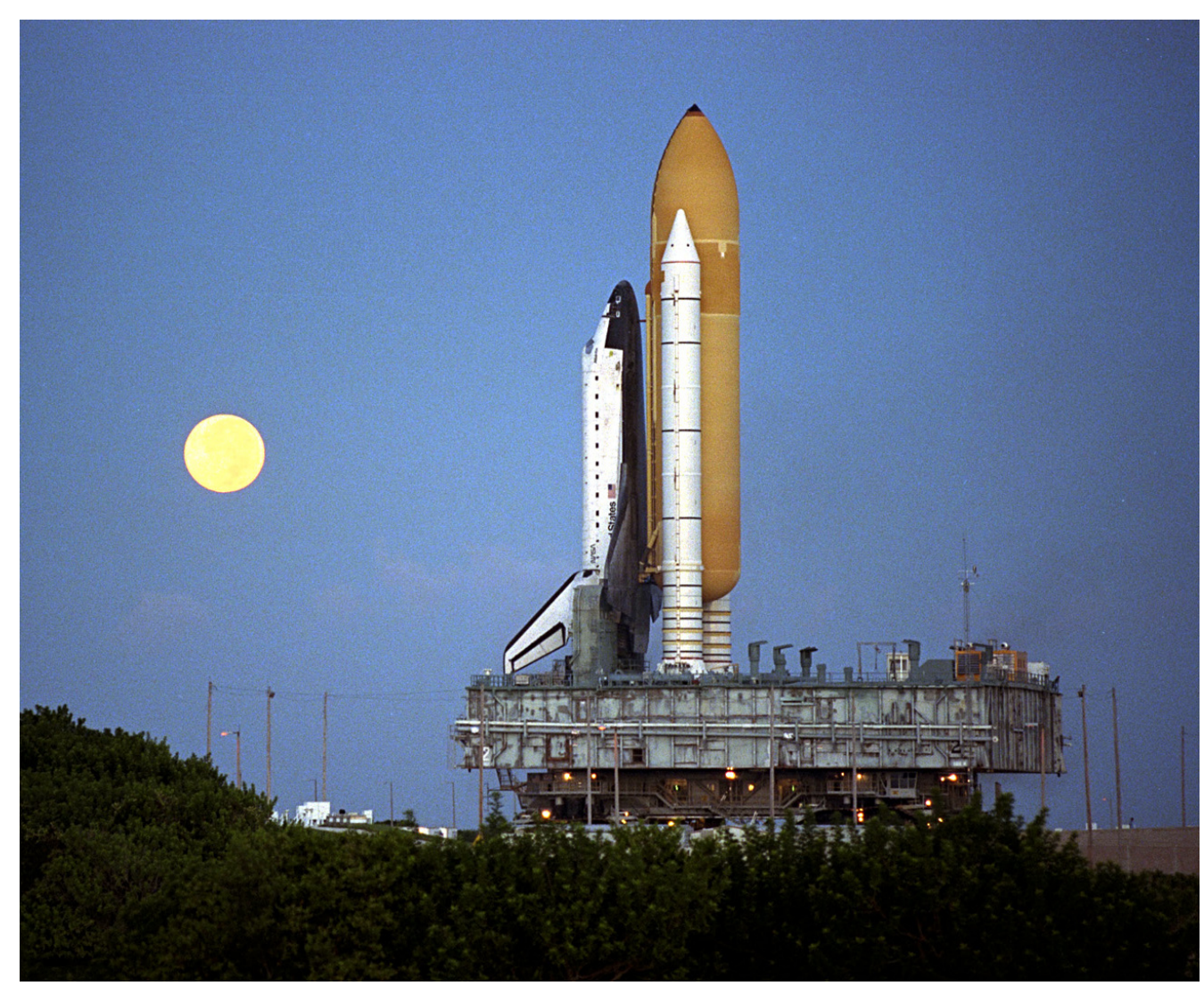




\section{Why did it take so long?}

1. The planned date for the start of TACAN phase-out in the Federal Radionavigation Plan slid to the right and is now TBD.

2. Continued TACAN availability and the excellent performance of the legacy navigation system made GPS a lower priority.

3. In 1998 the Shuttle Program decided to delay certification and perform additional flight and ground testing.

4. Loss of Columbia. 


\section{Each Orbiter is equipped with GPS.}

Atlantis and Discovery have one GPS receiver. GPS is processed in parallel with TACAN, IMU, drag altimeter, and air data.

Endeavour has three GPS units and no TACANs. GPS is processed in parallel with IMU, drag altimeter, and air data.

GPS is not processed once MLS is available.

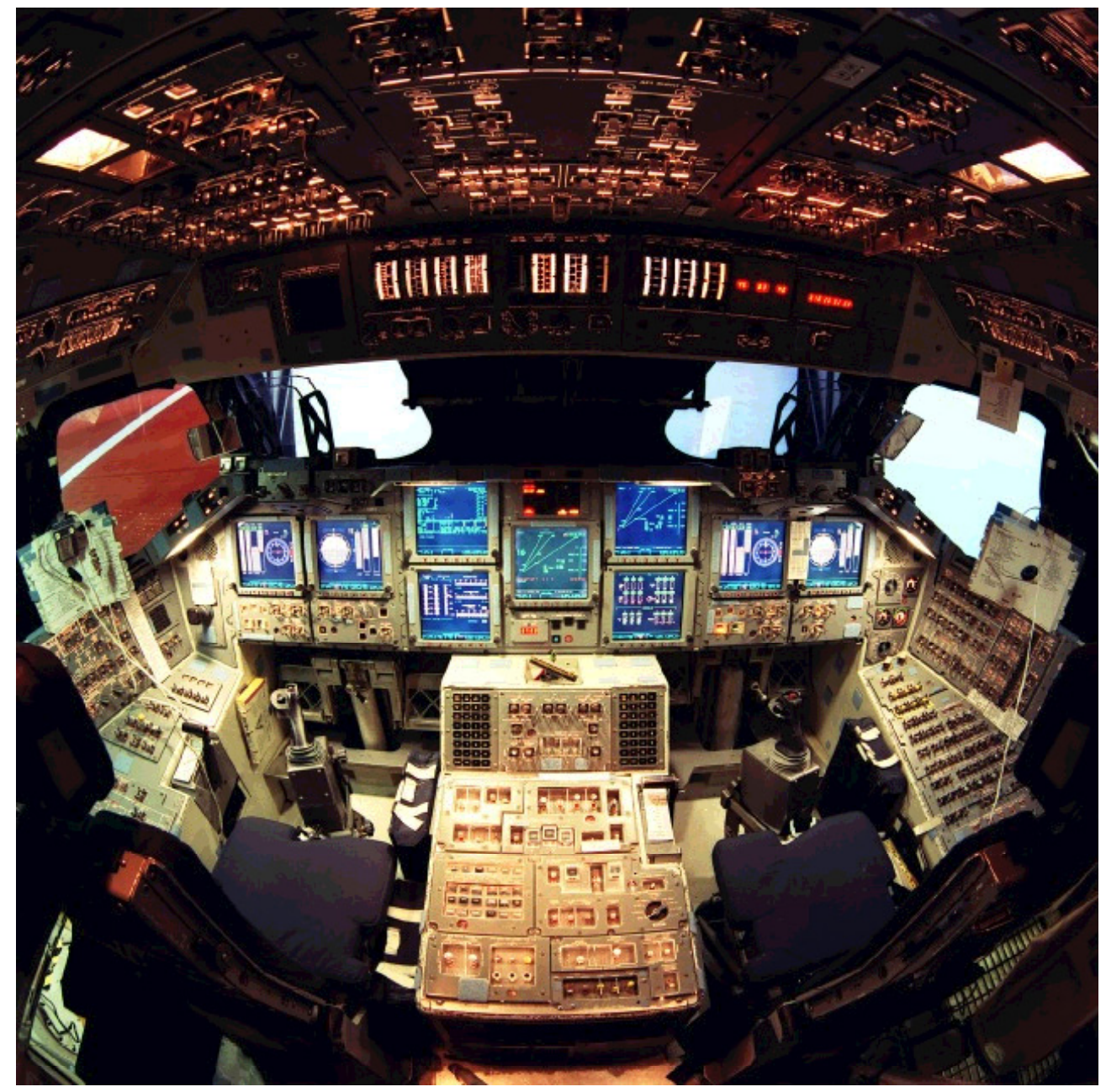




\section{In 2006 and 2007 Atlantis and Discovery processed GPS during entry to build confidence before the first no TACAN flight by Endeavour.}

GPS processed before the deorbit burn and during entry after confirmation of performance with ground radar tracking.

TACAN still processed.

STS-121 - GPS to backup computer.

STS-115 - GPS to primary computers.

STS-116 - GPS to primary computers.

STS-117 - GPS to primary and backup computers. 


\section{STS-116 Navigation Events (Dec. 2006)}

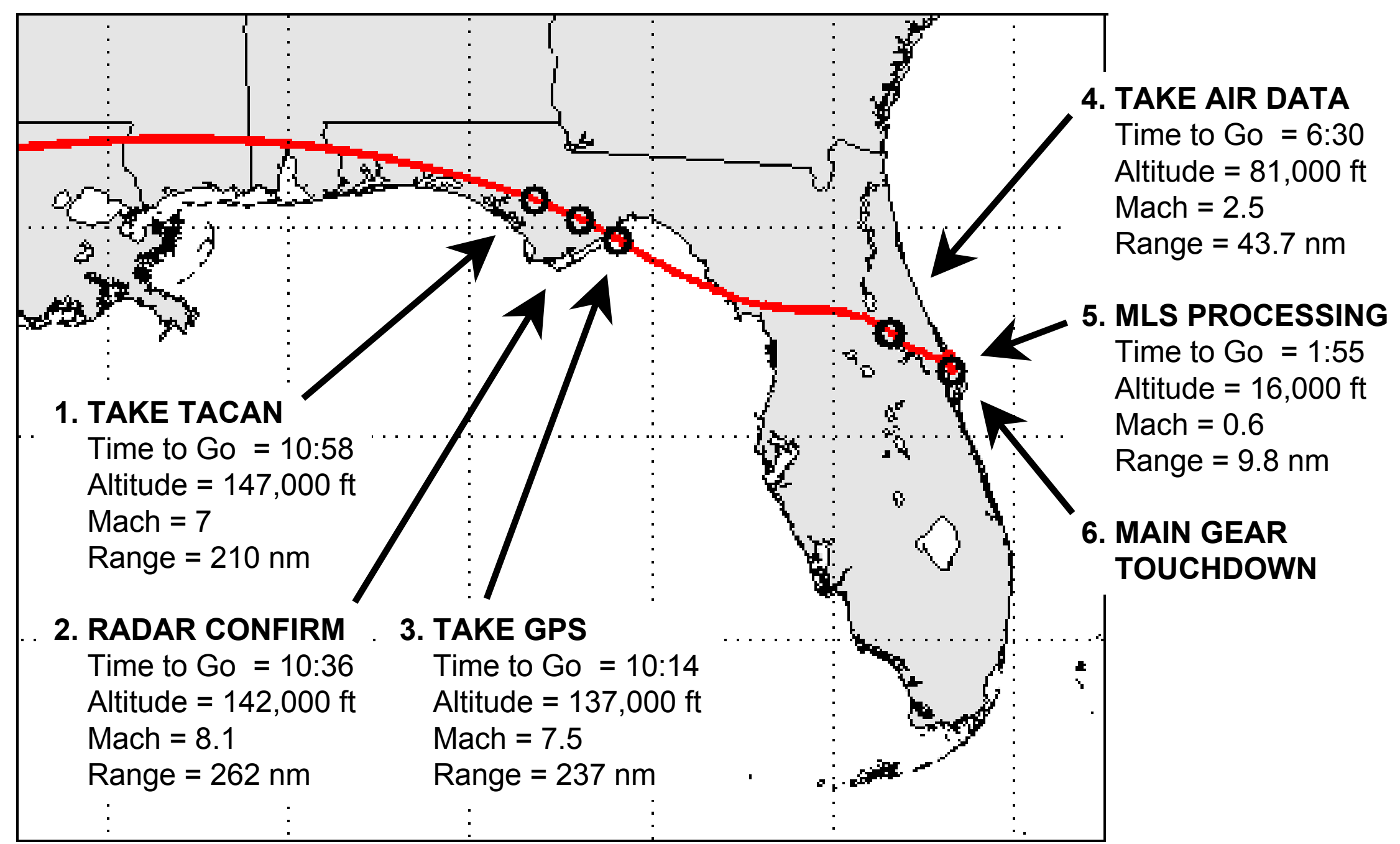




\section{STS-116 Best Estimate of Trajectory Position Compare With Primary Computer Navigation}
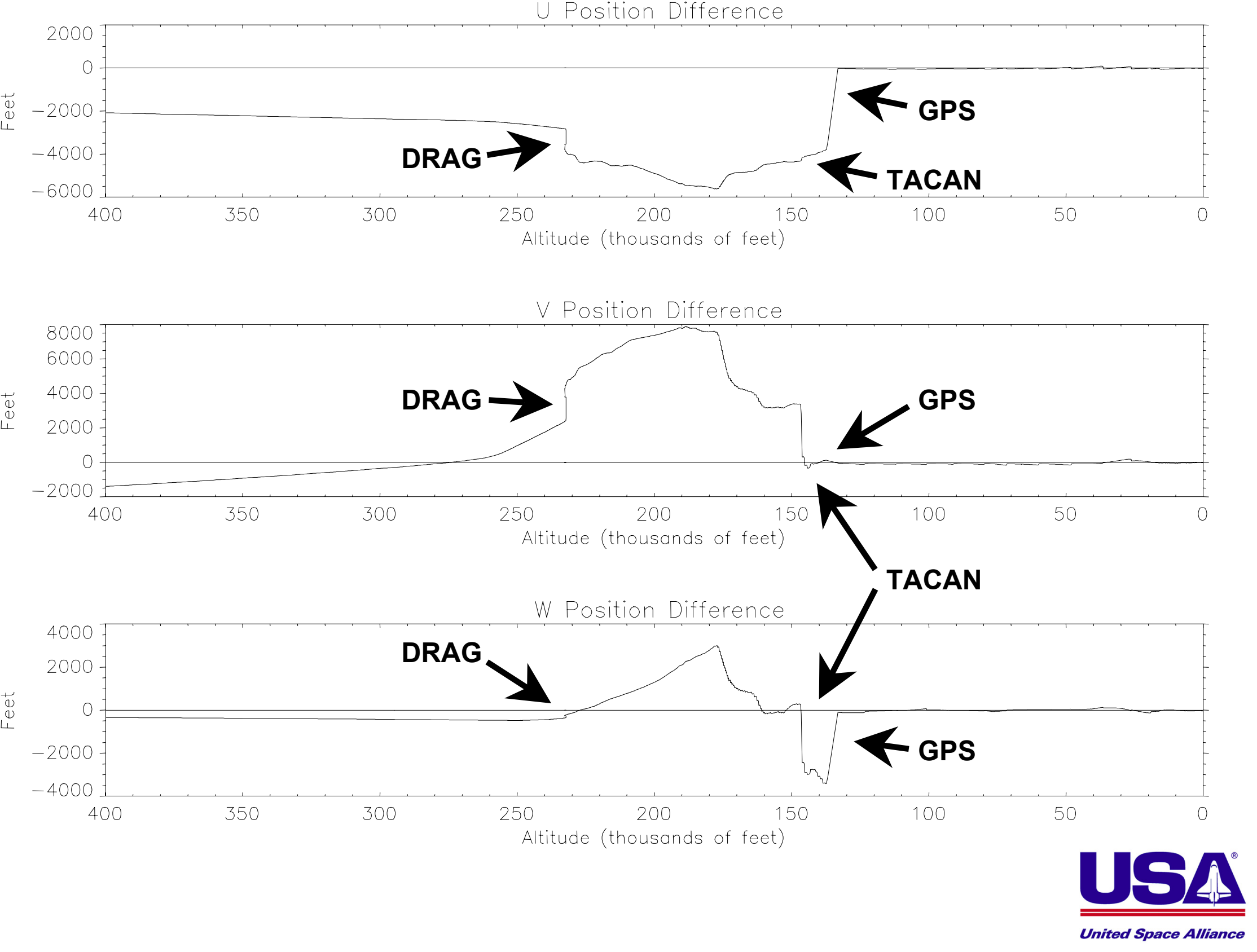


\section{STS-118 Flight of Endeavour}

GPS updates to the primary computers before the deorbit burn and during entry after confirmation of performance with ground radar tracking.

Primary computer took GPS updates in parallel with IMU, drag altimeter, and air data. GPS not processed once MLS was available.

State vector transfers from the primary computers to the backup computer due to lack of TACAN.

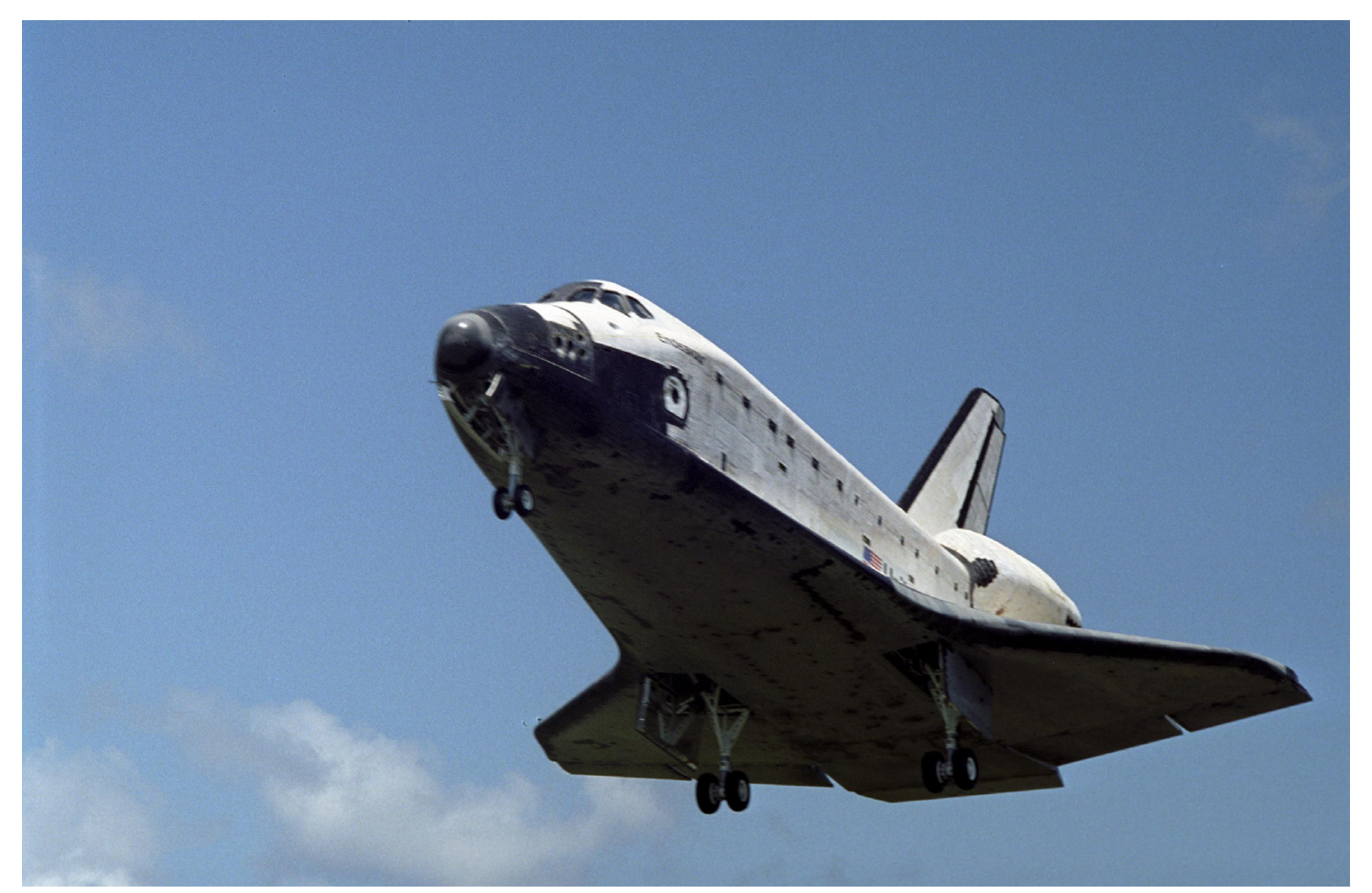




\section{STS-118 Navigation Events (Aug. 2007)}

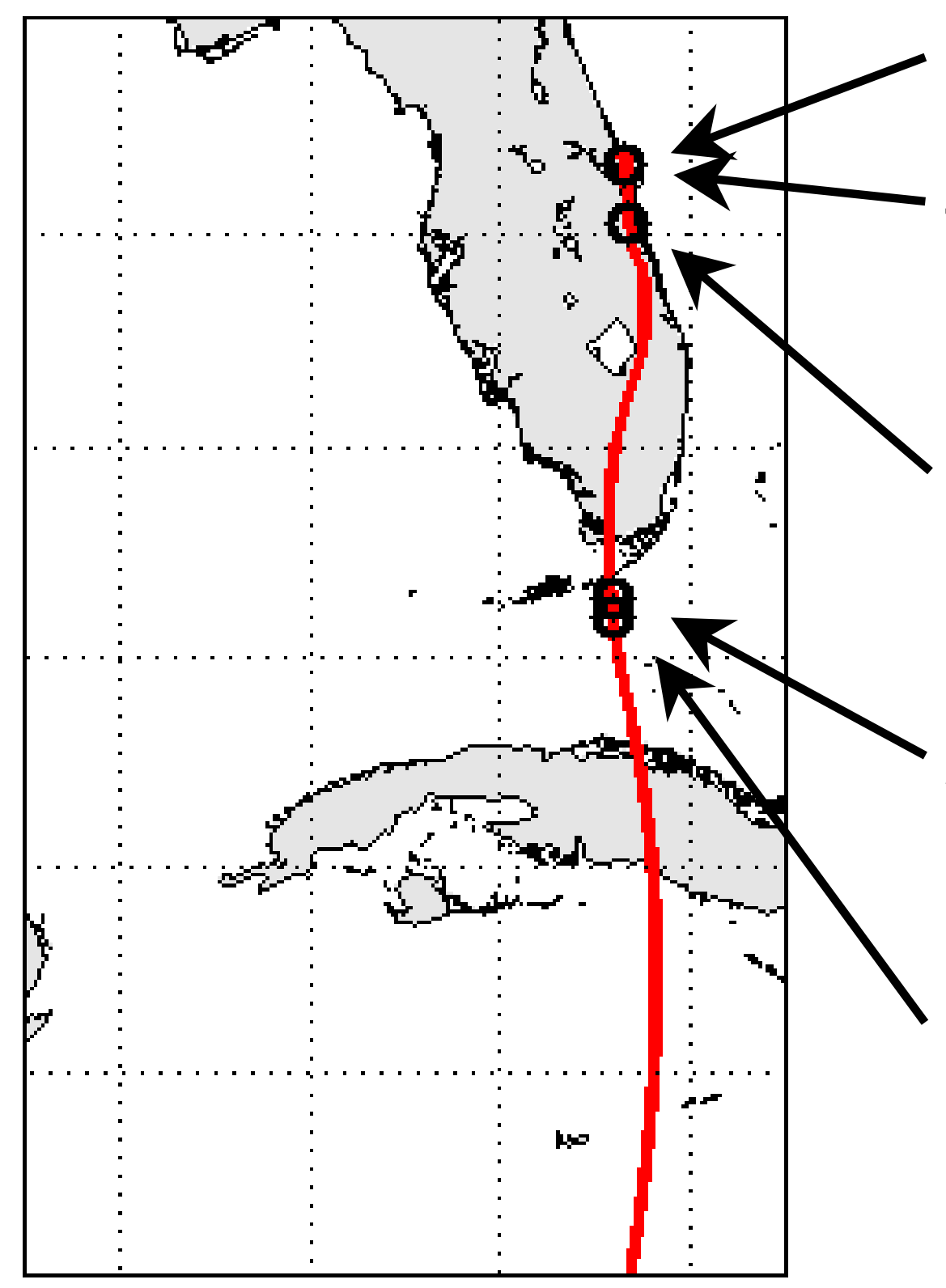

\section{MAIN GEAR}

TOUCHDOWN

4. MLS PROCESSING

Time to $\mathrm{Go}=2: 24$

Altitude $=22,000 \mathrm{ft}$

Mach $=0.7$

Range $=10.7 \mathrm{~nm}$

3. TAKE AIR DATA

Time to $\mathrm{Go}=6: 50$

Altitude $=81,000 \mathrm{ft}$

Mach $=2.4$

Range $=37.6 \mathrm{~nm}$

2. TAKE GPS

Time to Go $=10: 47$

Altitude $=137,000 \mathrm{ft}$

Mach $=7.9$

Range $=245 \mathrm{~nm}$

1. RADAR CONFIRM

Time to $\mathrm{Go}=10: 56$

Altitude $=142,000 \mathrm{ft}$

Mach $=8$

Range $=255 \mathrm{~nm}$ 


\section{STS-118 Best Estimate of Trajectory Position Compare With Primary Computer Navigation}
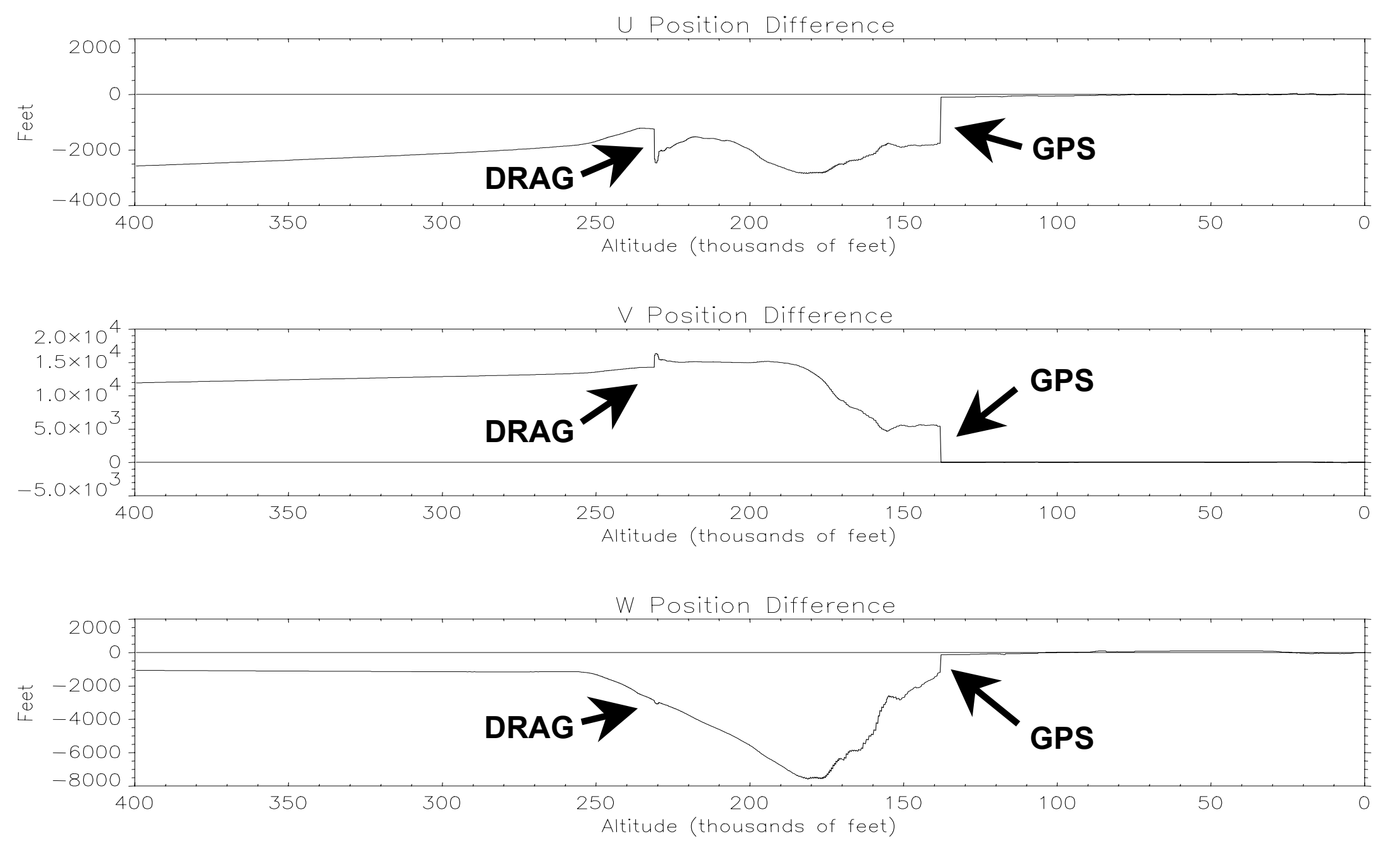


\section{Shuttle nav versus Best Estimate of Trajectory}

shows MLS provided little accuracy improvement due to GPS.

MLS processing began and GPS stopped at 22,000 feet.

$\begin{array}{lrr} & \text { Before MLS } & \text { After MLS } \\ \text { Radial } & -36 \text { feet } & -1 \text { feet } \\ \text { Down-track } & -104 \text { feet } & -103 \text { feet } \\ \text { Cross-track } & 66 \text { feet } & 56 \text { feet }\end{array}$




\section{NASA GPS Lessons Learned Documents}

GPS Lessons Learned From the ISS, Space Shuttle and X-38

Lessons Learned From Seven Space Shuttle Missions

Three Years of Global Positioning System Experience on International Space Station

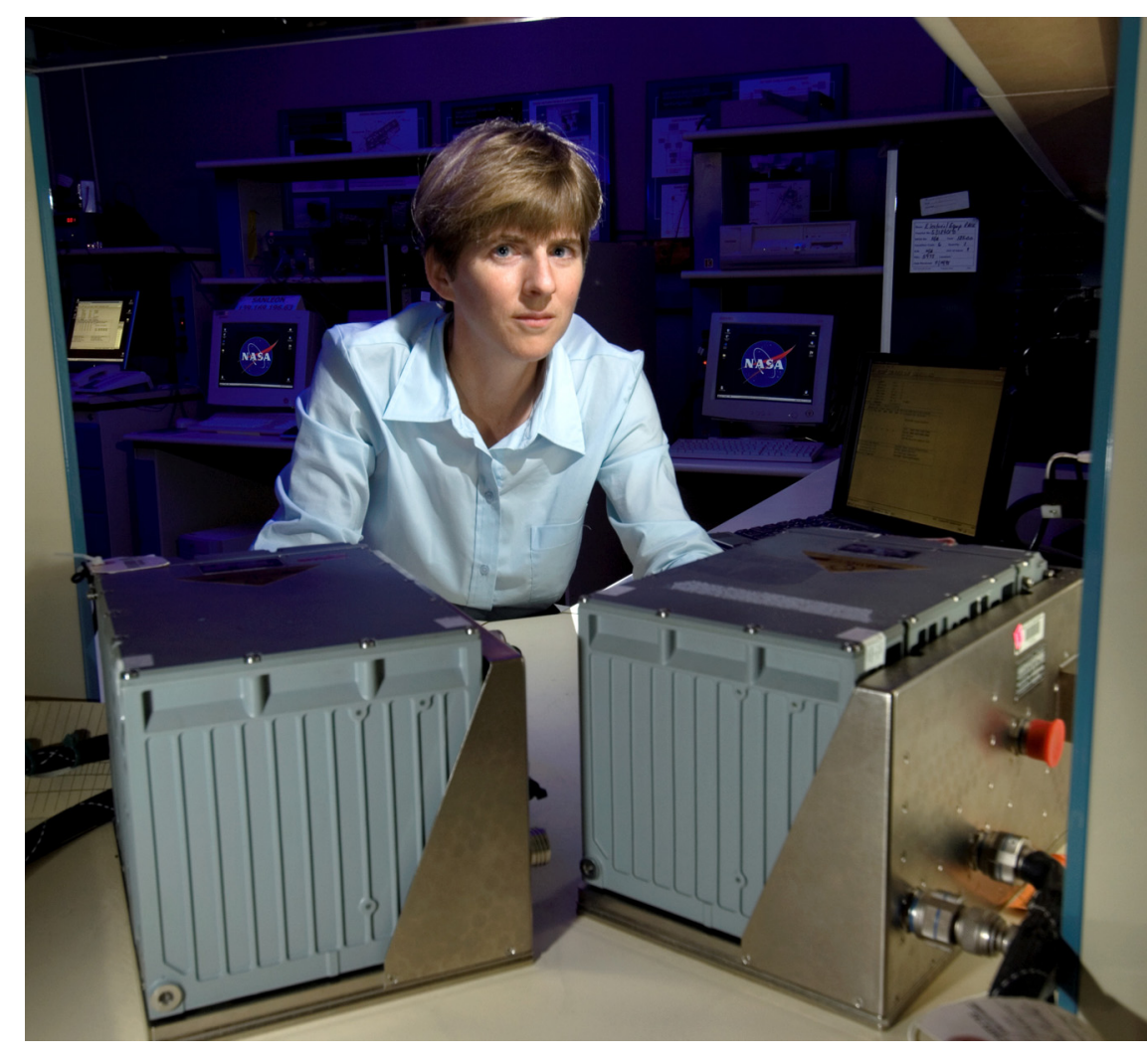


GPS lessons learned are being applied to development of the Orion spacecraft.

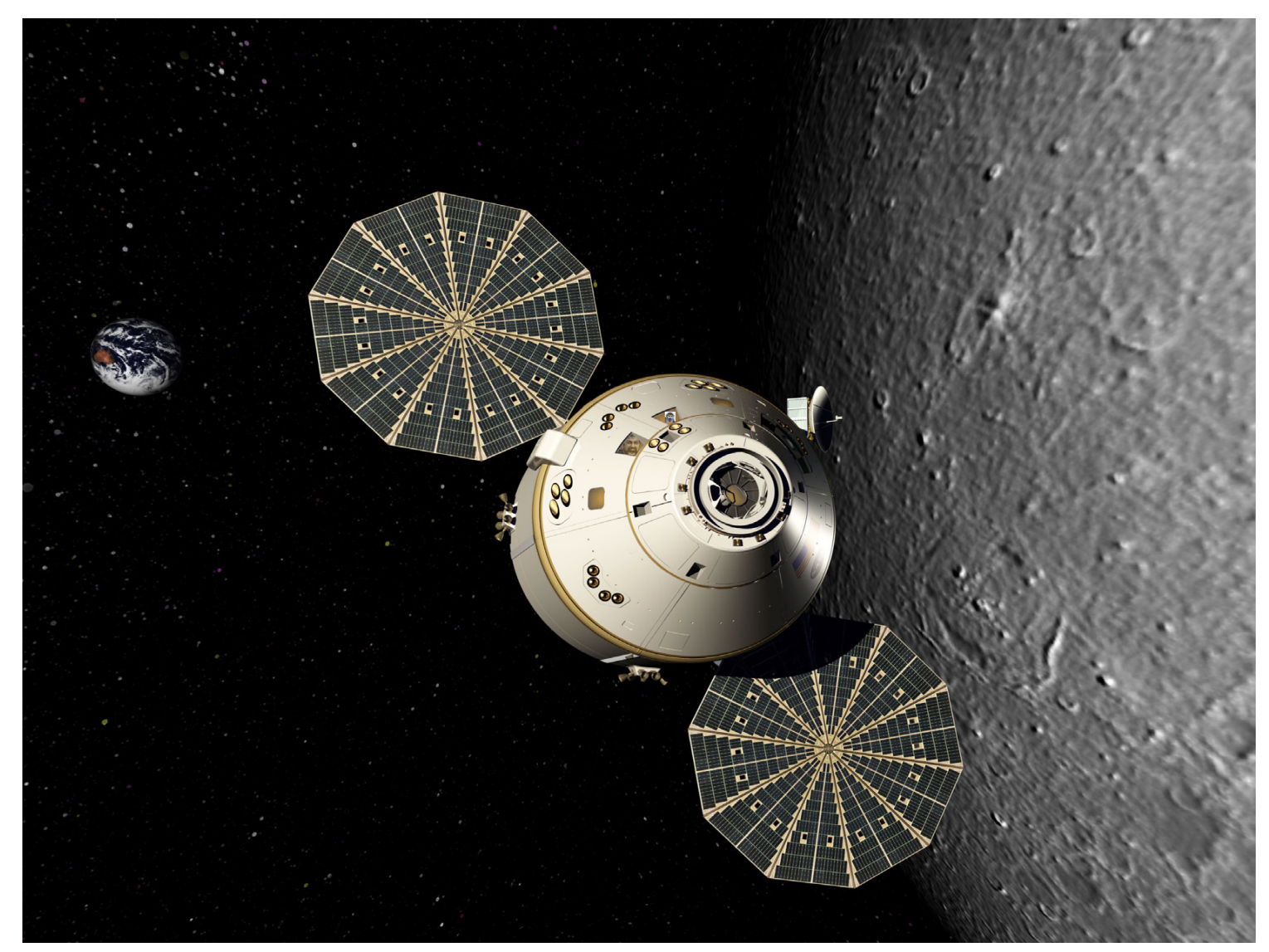




\section{Summary}

GPS is a TACAN replacement on Endeavour.

Discovery and Atlantis have GPS and TACAN.

Integration architecture permitted test flights without having to use GPS.

Ramp-up flights using GPS and TACAN in parallel built confidence before first TACAN replacement flight.

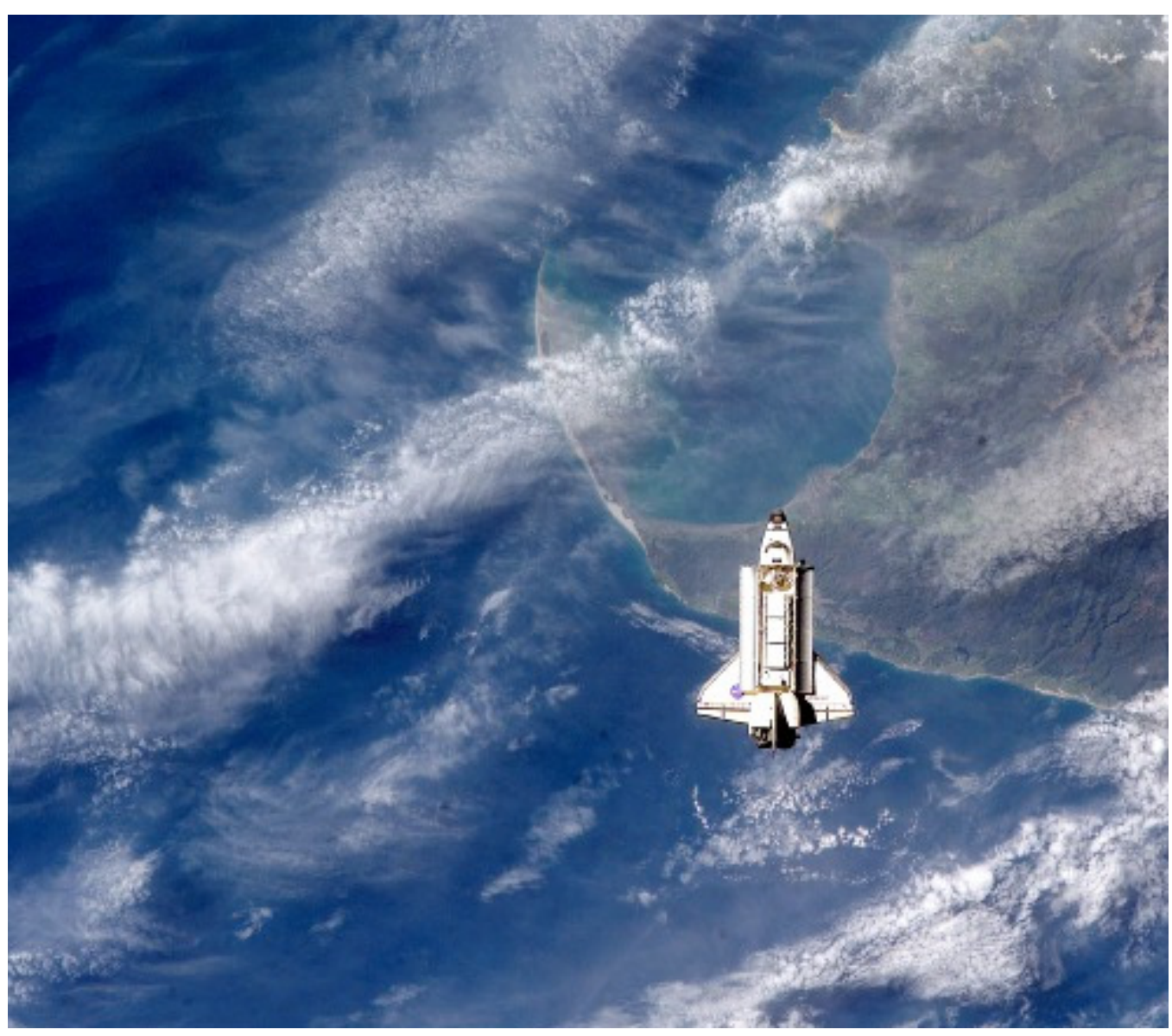

GPS performance is excellent. 
Questions

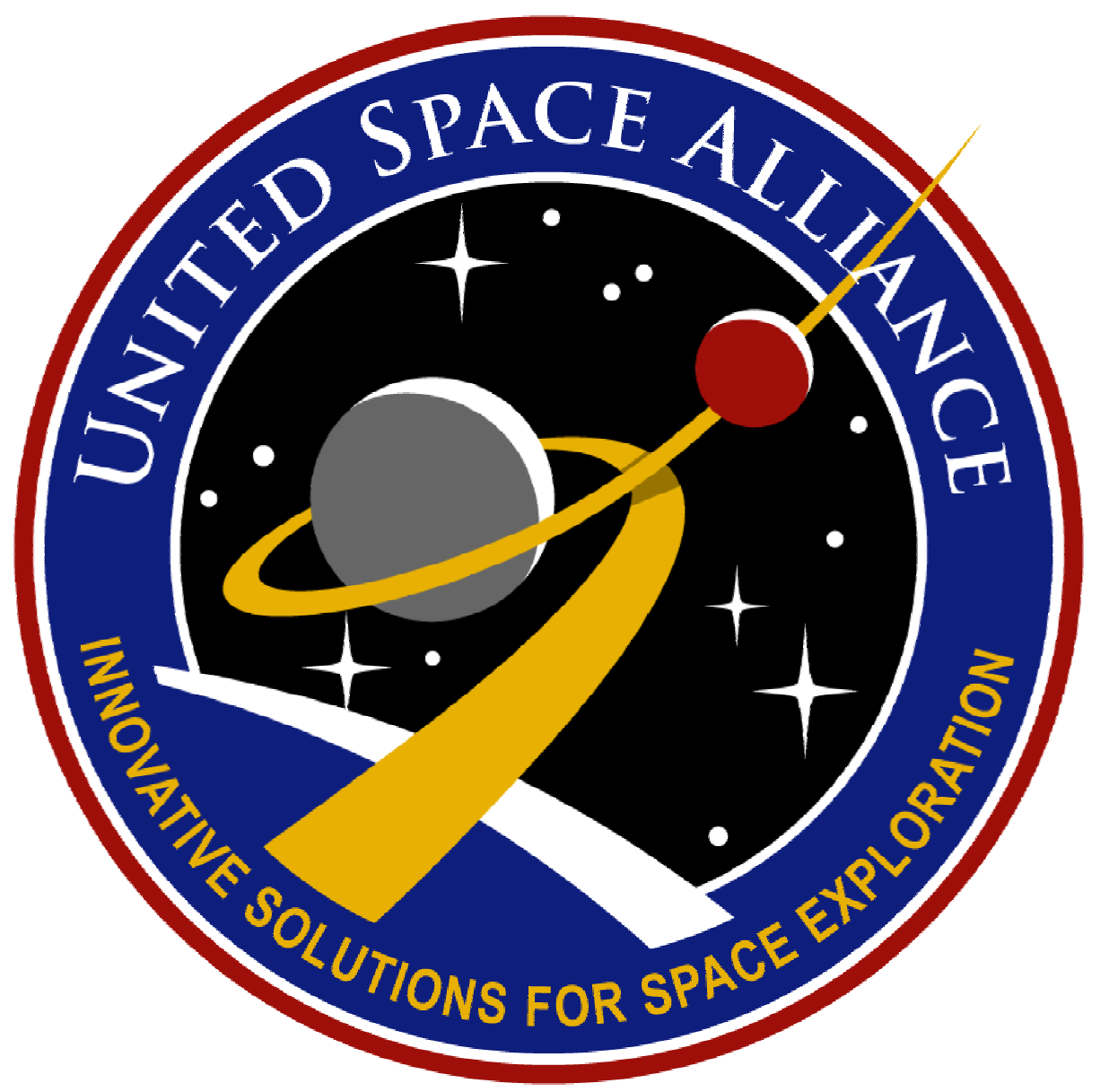

